\title{
دور ريادة الأعمال فى تحقيق أهداف التنمية المستدامة (مع الإشارة الى الواقع المصرى)
}

أ.م.د سمر الأمير غازي عبد الحميد أ.م.د فاروق فتحي السيد الجزار

أستاذ الإقتصاد المساعد

كليه التجارة جامعه طنطا
أستاذ الإقتصاد المساعد الميز

كليه التجارة جامعه طنطا 


\section{ملخص البحث:}

يهدف هذا البحث الى دراسة دور ريادة الاعمال فى تحقيق أهداف التنمية المستدامة مع الإشارة الى الواقع المصرى بإستخدام المنهج الفرضى الحديث وتم إستخدام سببية جرانجر بالاضافة الى التحليل

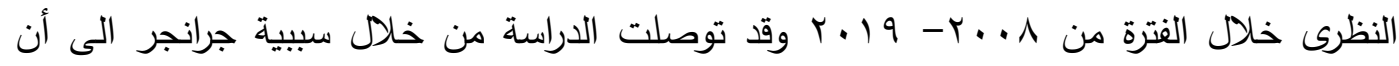
ريادة الاعمال تسبب التتمية البشرية وبالتالى تؤثر فى البعدين الاقتصادى و الاجتماعى من أبعاد التتمية المستدامة وأن ريادة الاعمل مسبب من مسببات النمو الاقتصادى وبالتالى تؤثر فى تحقيق التتمية المستدامة وأن العلاقة بين ريادة الاعمال ومدى تحقق الجودة البيئية وهى تمثل البعد البيئى للتتمية المستدامة تتجه من البعد البيئى الى ريادة الاعمال أى أن مدى توافر بيئة جيدة يدعم ريادة

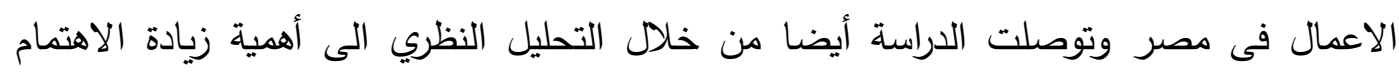
بالمشاريع الصغيرة والمتوسطة وتفعيل تفكير الثباب وتطوير حاضنات الثباب وتطوير منظومة التخطيط الكلى والتركيز على التعليم الفني والحد من الروتين الادارى فى إنجاز المعاملات وتوسيع نطاق الدعم والاتجاه الى تسجيل المشروعات قانونيا وتشجيع رواد الأعمال على ابتكار مشروعات

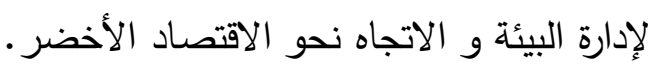

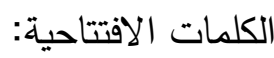
ريادة الأعمال - التتمية المستدامة - سببية جرانجر - الإقتصاد الأخضر - البعد البيئى- البعد الإقتصادى - المشاريع الصغيرة- حاضنات الثباب- التعليم الفني- الدعم. 
منذ أن أطلقت الامم المتحده مفهوم التتميه المستدامه، وتسابقت الدول نحو تطبيق هذا المفهوم وفقا لما يتوافق مع طبيعه وهيكل إقتصادياتها، على الرغم من أن محاور التتميه المستدامه واحده وفقا بما وضعته الامم المتحده، ألا أن الاختلاف فقط هو فى أليه التطبيق وفقا لرؤيه وإستراتيجيه كل دوله

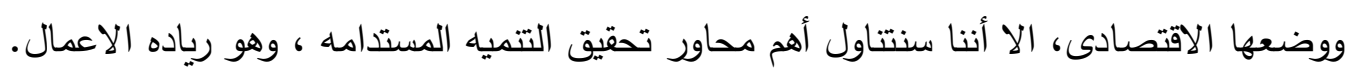
لاشك أن مصطلح رياده الاعمال شهد تناولا كبيرا الفتره الماضيه ليس فقط خلال العالم ولكن أيضا فى مصر،بالاضافه الى أن كافه الدول أصبحت تولى ملف رياده الاعمال إهتماما كبيرا مما ينعكس على تحقيقها للتميه المستدامه وفى هذا السياق فأن رياده الاعمال أصبحت مجالا قويا ومعبرا نحو تحقيق التتميه المستدامه، وهذا بالتأكيد راجع لقدرتها على أحداث تأثيرا أيجابيا داخل مجتمع التهاتيات الاعمال العالمى، هذا بالاضافه لما تقدمه من أطار جديد للابتكار والتتميه،وقدرتها على أن تقدم حلولا واقعيه تتماشى مع كافه المشكلات والتحديات الاقتصاديه فى كافه قطاعات الاقتصاد. وسوف يتم تتاول الدراسه عن طريق التعرف على مفهوم رياده الاعمال ومفهوم التتميه

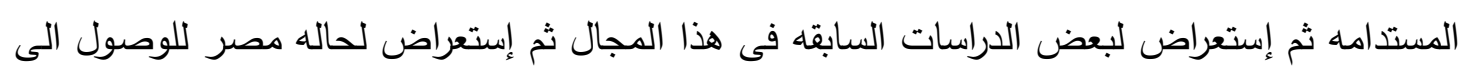
الاتجاهات الحديثه. - اته

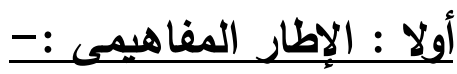

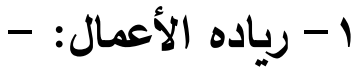

عند البحث عن مفهوم ريادة الأعمال أو رواد الأعمال فى التحليل الاقتصاد نجد أنه لايوجد تعريف

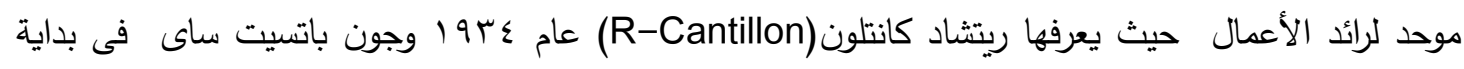
القرن التاسع عشر ، وعبرا عنها بنوع من الثخصية التى على إستعداد لتأسيس مشروع جديد أو مؤسسة وتقبل

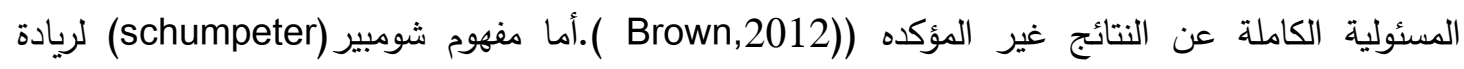

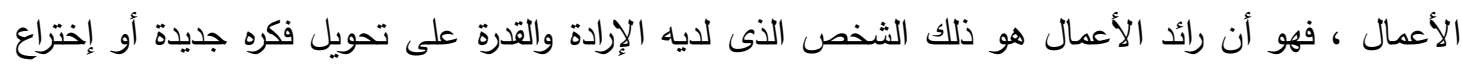

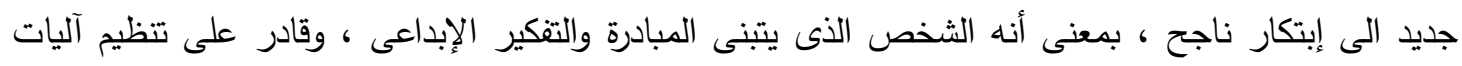

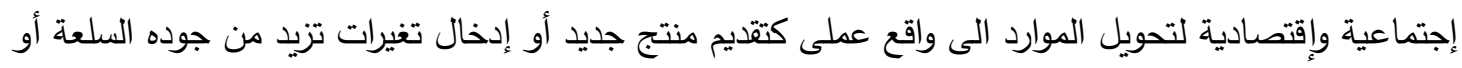
المنتج أو تتفيذ أشكال تتظيمية جديده فى الصناعة (Maia, 2005 ) وبذلك أصبحت الرياديه إحدى عوامل

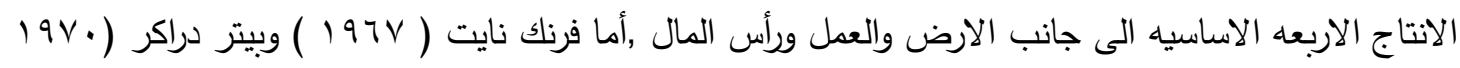

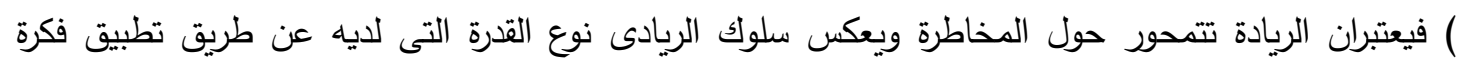

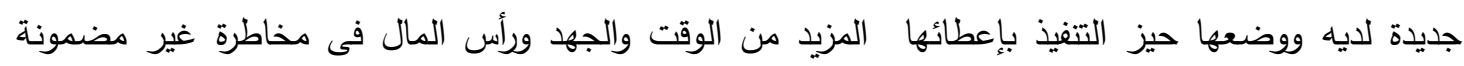

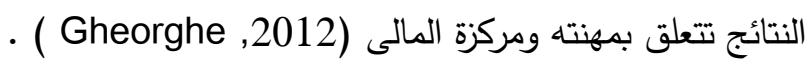


وهناك وجهة نظر آخرى تقوم بتعريف ريادة الأعمال من حيث الحجم على أنها الشركات الصغيرة والمتوسطة حيث أن خلق المشاريع الجديدة هو جوهر ريادة الأعمال حيث أن رواد الأعمال هم الأفراد المدفوعون لتعني بالفرص الذين يقودون التغير الإقتصادى من خلال شركات جديدة مبتكره ( يوسف 9 ( ـ ب ) ) . وعلى ذلك يمكن تعريف ريادة الأعمال على أنها" الأفكار الجديدة أو الطرق التى تمكن من إنشاء شركة

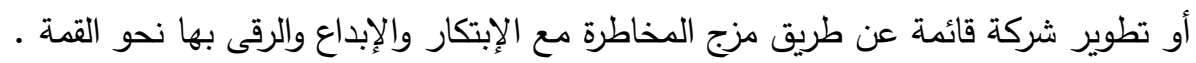
ويمكن أن نتوصل إلى أن ريادة الأعمال هى الاعتماد على مشروعات الإتىر والإعلى صغيرة أو متوسطة محدودة رأس المال ، وأفكار هذه المشروعات تتسم بالإبداع ، ويكون الأساس فيها رائد الأعمال الذى الأى يتسم بالموهبة الثخصية ومهاراته وقدرته على إكتشاف الفرصة وتحويلها الى مشروع يحقق ربح وقادر على النمو مع تحمل المخاطرة والمجازفة فى ظل ظروف عدم التاأكد . ونجد أن مشروعات ريادة الأعمال من أهم الأعمدة الرئيسية فى اقتصاديات العالم المتقدمة منها والنامية لما قد تحققه من :

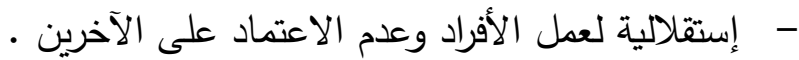
- - توفير فرص للنمو وتحقيق الإنجازات . - - - المساهمة فى خدمة المجتمع وتشجيع التصنيع ل

\section{r - التنمية المستدامة:}

لقد تم تعريف مصطلح التتمية المستدامة من قبل العديد من الباحثين والمؤسسات العلمية. حيث تم تعريف التتمية المستدامة سنة 19Av فى تقرير اللجنة الدولية للبيئة والتتمية المعرف بـ (تقرير لجنة برونتلاند) على أن التنمية المستدامة هى:

التتمية التى تقى بإحتياجات الجيل الحالى دون أن يعرض للخطر أو الضرر قدرة الأجيال التالية عن

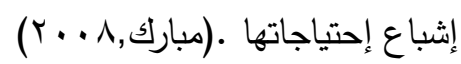

وكذلك حصر تقرير الموارد العالمية الذى نشر سنه ب991 المختص بدراسة موضوع التتمية المستدامة

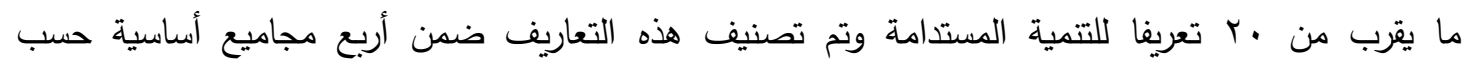

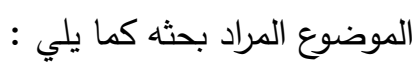

- تعريفات ذات طابع إقتصادى : حيث أن التمية المستدامة بالنسبة للدول المتقدمة يعتبر إجراء لتقليص مستديم لإستهالاك الطاقة والموارد الطبيعية ـ مع إحداث تغير جذرى للأنماط الاستهلاكية والانتاجية السائدة , أما الدول النامية فتعنى التتمية المستدامة ترشيد توظيف الموارد من أجل التخفيض من حده الفقر ورفع المستوى المعيشي . - تعريفات ذات طابع إجتماعى : تهدف التتمية المستدامة إلى الاهتمام بالعنصر البشرى من خلال تحقيق الرعاية الصحية وإنشاء المدارس وتوفير فرص عمل . 
- تعريفات متعلقة بالبيئة : التتمية المستدامة تمثل الإستخدام الأمثل للموارد الطبيعية (الأرض ,

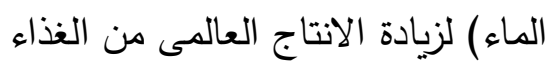

- تعريفات ذات طابع تقنى : التتمية المستدامة هى التى تعتمد على التقنيات النظيفة وغير المضرة

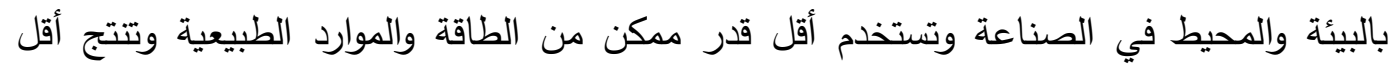
إنبعاث غازى ملوث وضار بطبقة الأوزون .

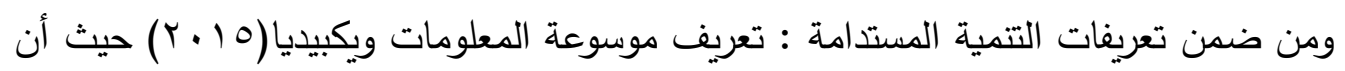
التتمية المستدامة هى عملية تطوير الأرض والمدن والمجتمعات وكذلك الأعمال التجارية بشرط أن تلبي إحتياجات الحاضر دون المساس بالاجيال القادمة .

وتعرف منظمة الأغذية والزراعة (الفاو) التمية المستدامة (الذى تم تبنيه في عام 919 (1) كما

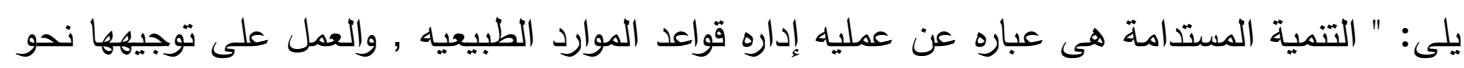
التغير التقنى و المؤسسى بصوره تضمن تحقيق وإستمرار إثباع الحاجات البشريه للاجيال الحاليه

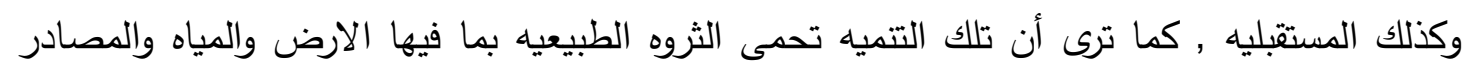

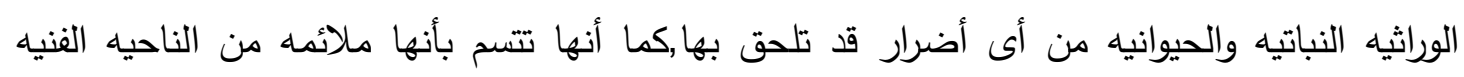
والتقنيه والاقتصاديه. (Acciona,2018)

يتضح لنا أن التمية المستدامة في الواقع هى " مفهوم شامل يرتبط بإستمرارية الجوانب

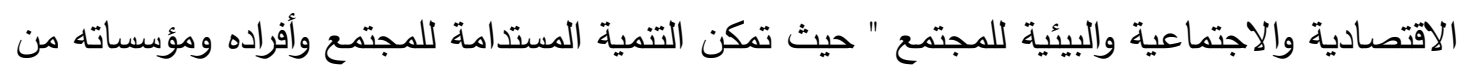

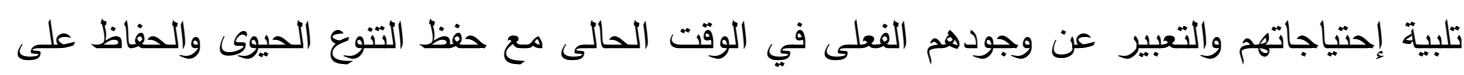

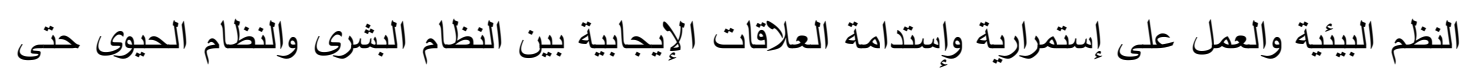

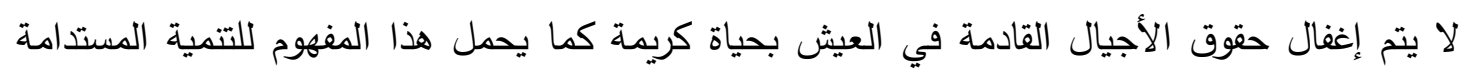

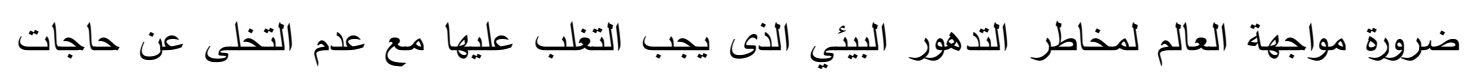

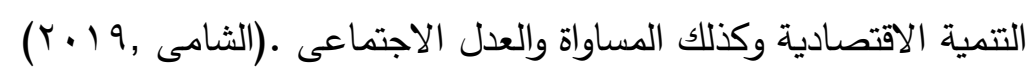

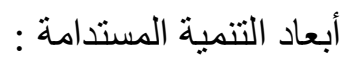
التتمية المستدامة هى التتمية التى لا تركز على الجانب البيئي فقط وإنما تثمل جوانب

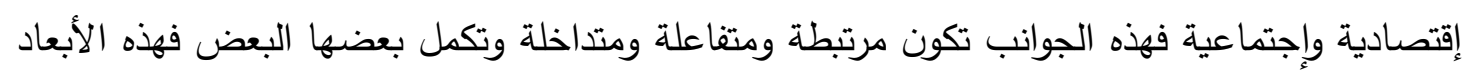
أشبه بالجذور التى تغذى التتمية الكستدامة وتساعد على تحقيقها. البعد الاقتصادى للتنمية : إن البعد الاقتصادى يتعلق بمحاولة إيقاف تبديد الموارد الطبيعية عن طريق إجراء تخفيضات

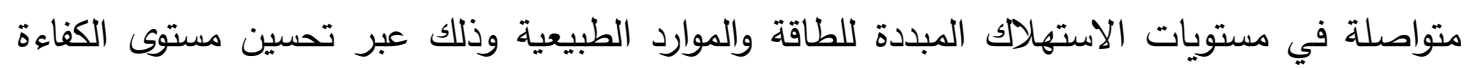

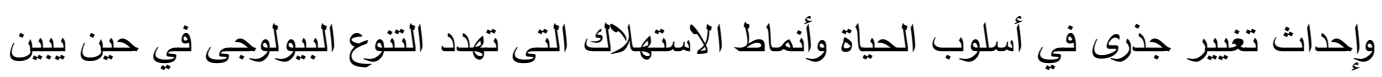




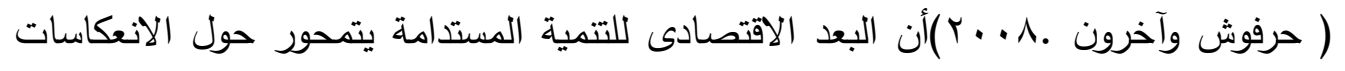

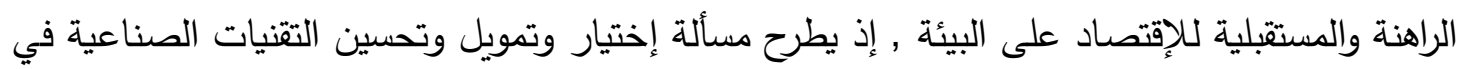
مجال توظيف الموارد الطبيعية . البعد الإجتماعى للتنمية :

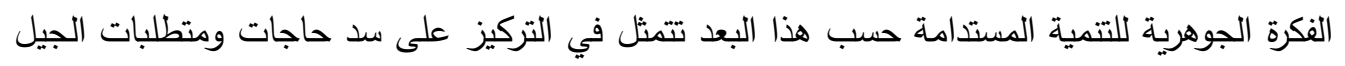

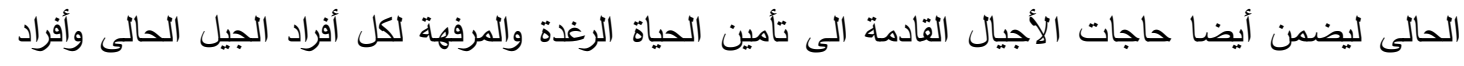

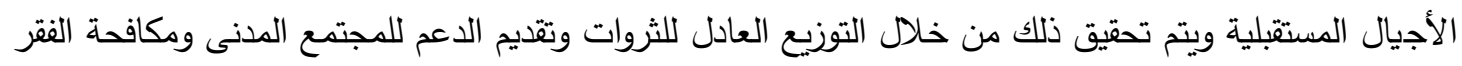

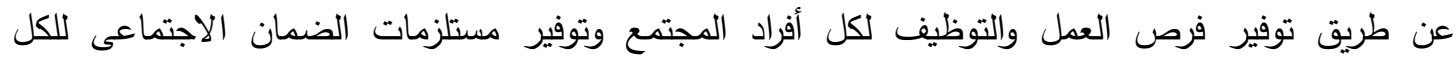

. (www.eeagrants.org)

\section{البعد البيئي للتنمية : البية}

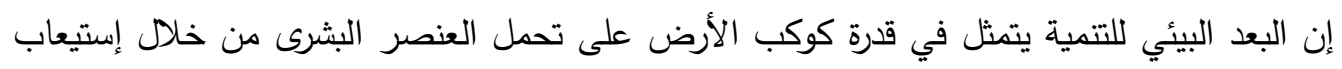

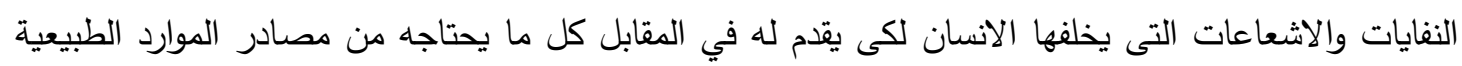

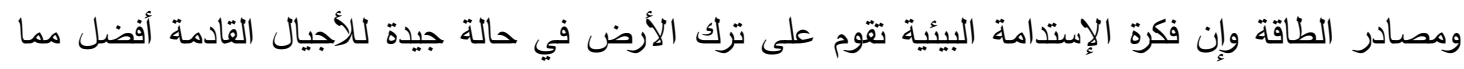

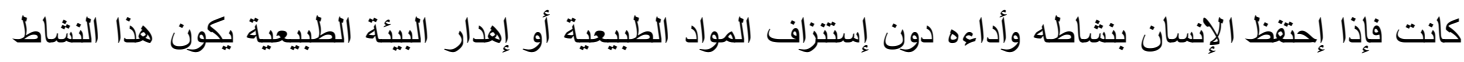

مستدام طبيعيا (www.Sustainability) ولنجاح عملية التنمية المستدامة لابد من إرتباط هذه الأبعاد وتكاملها نظرا إلى الارتباط الوثيق بين

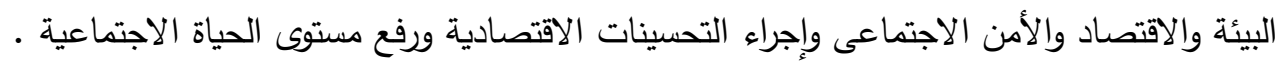

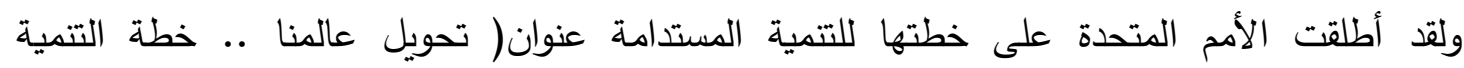

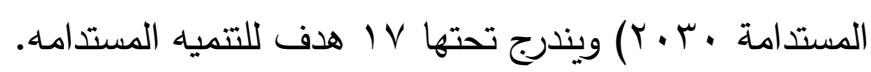

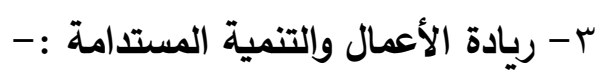

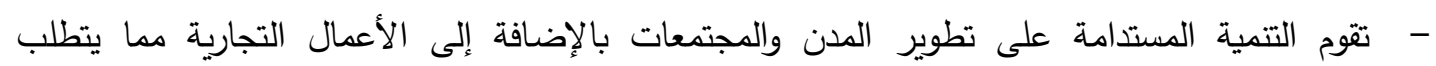

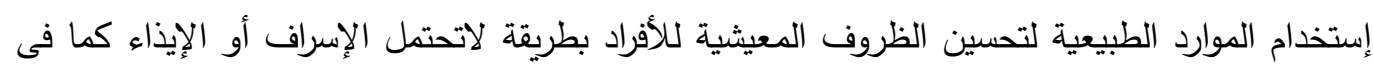

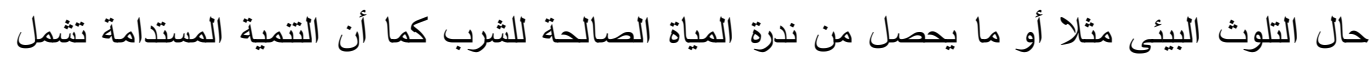
مجالات كثيرة مثل النمو الإقتصادى والتتمية الإجتماعية بالإضافة الى الحفاظ على البيأل البئة والموارد

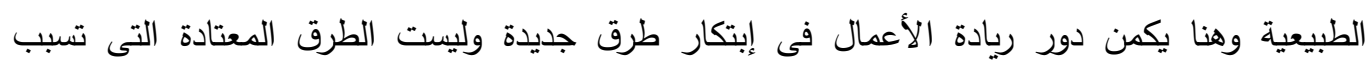

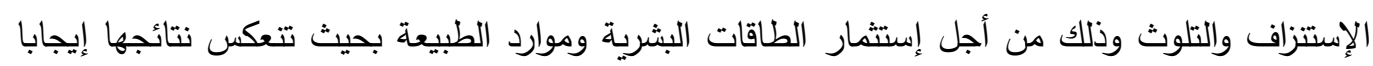

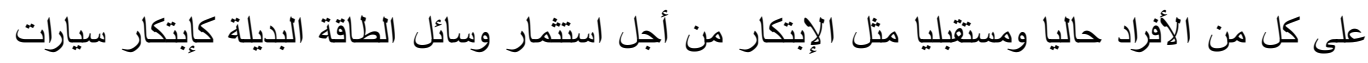

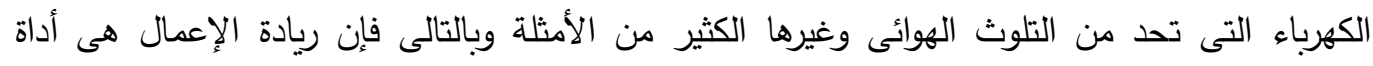

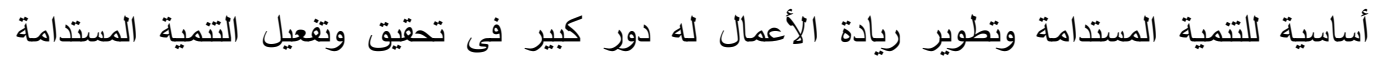

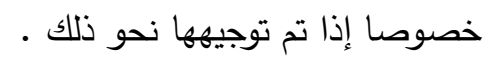


وعلى ذلك يمكن " وضع تعريف لإستخدام ريادة الأعمال فى تحقيق التمية المستدامة على أنه :إستخدام

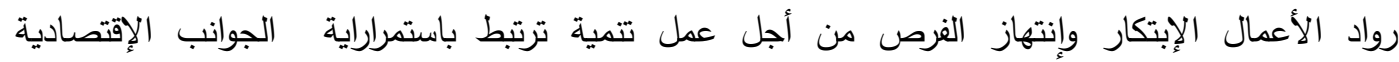
والإجتماعية والبيئية للمجتمع من خلال تمكين أفراد المجتمع ومؤسساته فى تلبية إحتياجاتهم .

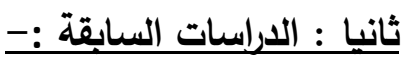

\begin{tabular}{|c|c|c|c|}
\hline & البعاد التمنية & أهداف التتمية & الدراسات السابقة \\
\hline & الإجتماعى البعد & 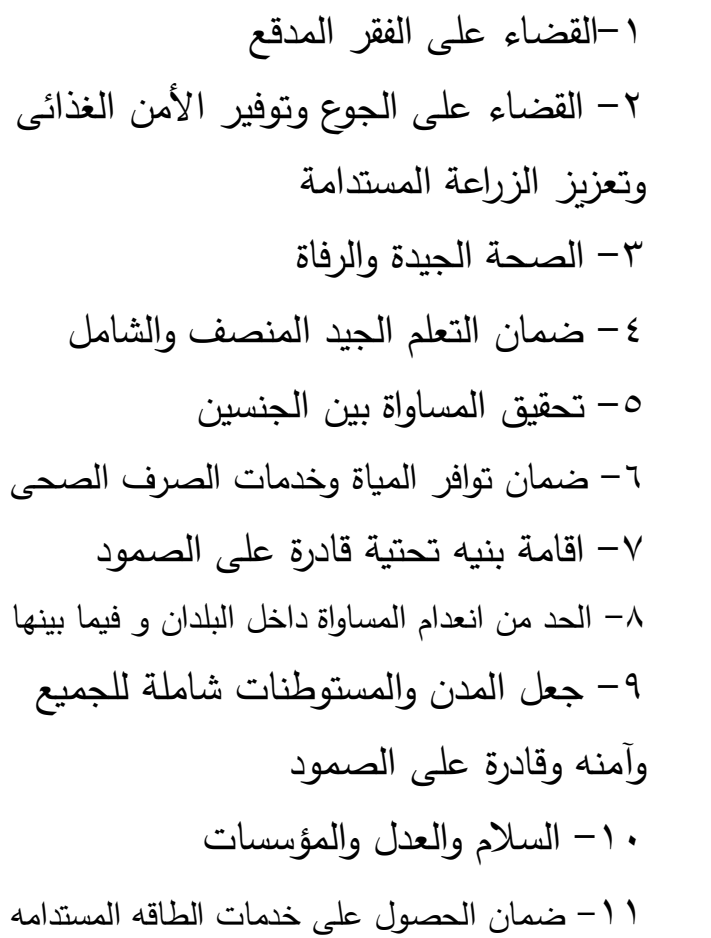 & 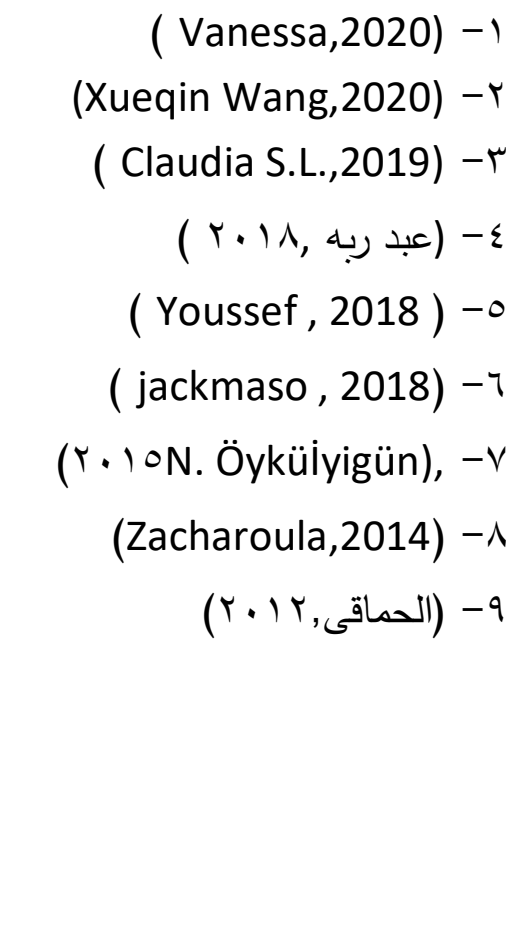 \\
\hline الأعمال & الإقتصادى البعد & 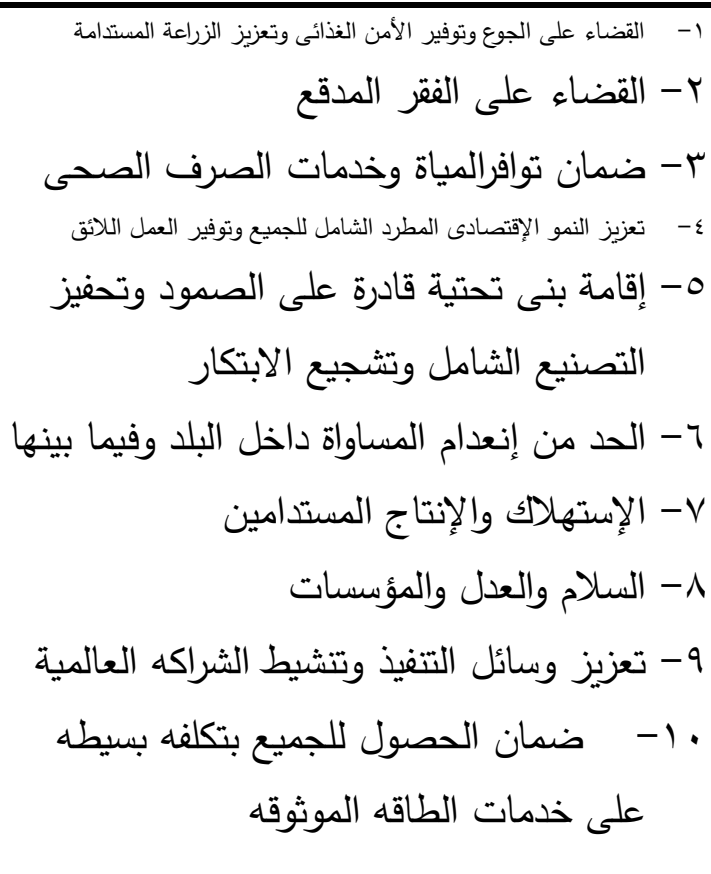 & 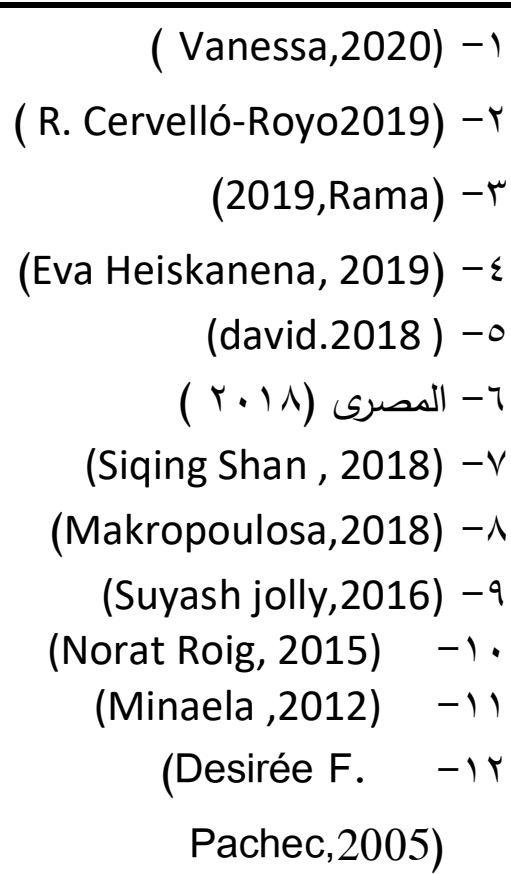 \\
\hline
\end{tabular}




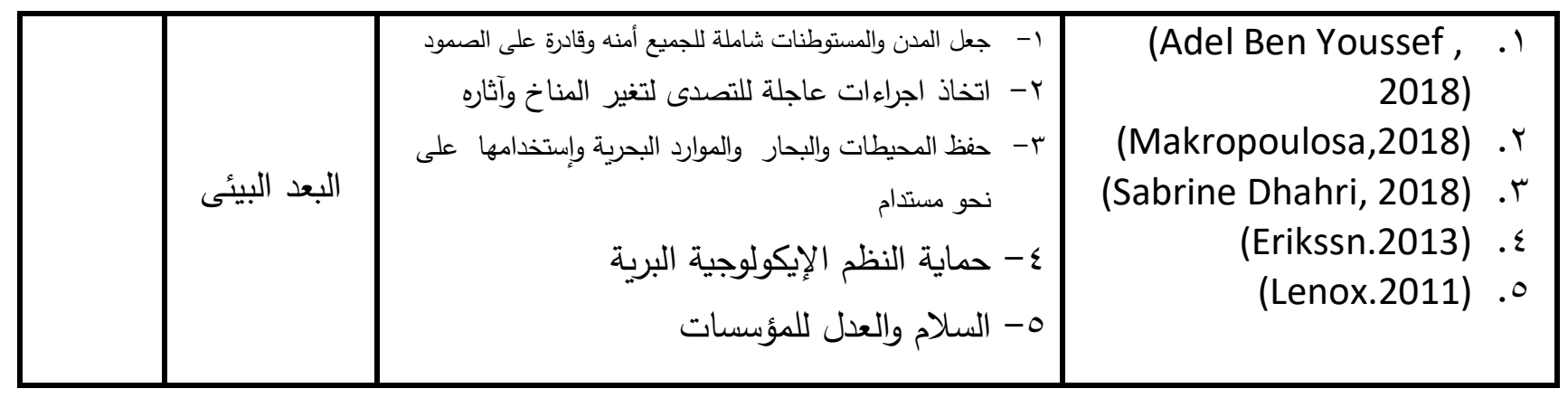

- دراسة (Vanessa,2020) -

هذه الدراسة تهدف إلى تعليم ريادة الأعمال وإزدهار تعليم ريادة الأعمال كمجال للبحث بسبب أهميتها العملية ودورها في تسريع الرفاهية الاقتصادية للاقتصاد العالمي. حيث لا يزال هنالك بعض العقبات لكى نفهم تماما طبيعة وقدرة تعليم ريادة الأعمال لتحويل المجتمع. الهدف من هذه الدراسة هو تسليط الضوء على الاتجاهات الحالية في تعليم ريادة الأعمال من خلال توفير بعض المسارات للبحوث المستقبلية التي تأخذ الإنسان كهدف للتعليم. سيساعد ذلك مزيدًا من الباحثين على تبني الطبيعة المميزة لريادة الأعمال من خلال ربطها بإتجاهات التوظيف الناشئة الجديدة مثل التحول الرقمي لمكان العمل. إقتراحات لكيفية إحتياجات تعليم ريادة الأعمال للمزيد من التقدم يتم إعطاءه كوسيلة لتشكيل التتمية

المستقبلية لهذا المجال

\section{(Xueqin Wang,2020) دراسة -}

هدفت هذه الدارسة إلى تحليل لتقارير الاستدامة من منظور ريادة الأعمال الاجتماعية " إلى بحث المسؤوليات الأساسية والممتدة (SDG 1 - SDG 16، بحث التعاون المحتمل ضمن سلسلة القيمة فيما يتعلق بتنفيذ أهداف التتمية المستدامة SDG 17) وتوصلت الدراسة إلى أن الصناعة البحرية الدولية تلعب دورًا مهمًا في المساهمة في الاستدامة العالمية من خلال تطبيق مفهوم الريادة الاجتماعية (SE)، تحليل محتوى لتقارير الاستدامة خلال الفترة

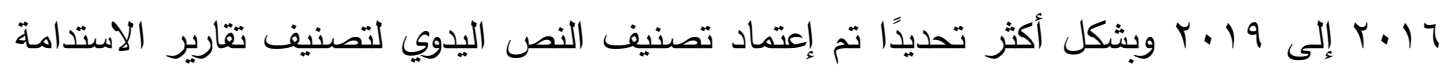
إستتادًا إلى VI هدف من أهداف التتمية المستدامة SDGs ، بالإضافة إلى تحديد الأدوار الرئيسية للصناعة البحرية المتعلقة بكل هدف من أهداف التتمية المستدامة SDG، إقتراح إطار عمل موحد، يشير إلى دوافع متنوعة ومستويات كلية لجهود الاستدامة التي تساهم بها الصناعة البحرية، بالإضافة إلى صياغة البعد النظري لمساهمة الصناعة البحرية في الإستدامة من منظور SE، بالإضافة إلي البعد الإداري فيما يتعلق بإستراتيجيات تخصيص الموارد من قبل الصناعة البحرية لتحقيق أهداف 
هذه الدراسة عن ماهو الجديد فى البحث عن ريادة الاعمال الزراعية على الرغم من أن البحث الريادي

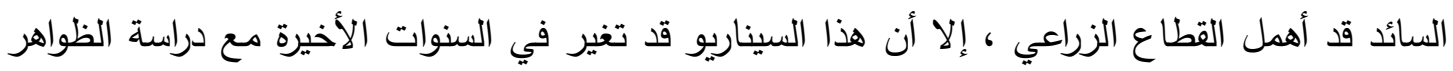

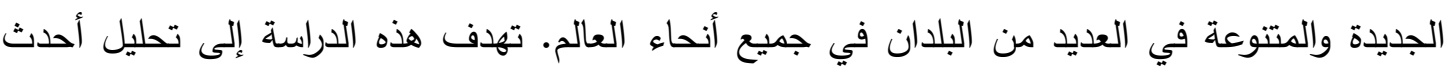
التطورات في ريادة الأعمال الزراعية من خلال منهجية مراجعة الأدبيات والمقالات التي تم استعراضها فئاء تم الحصول عليها من قاعدة بيانات Scopus ، التي تغطي المجلات من جميع المجالات. سمحت النتائج بتحديد ثلاثة مناهج رئيسية هي: (1) مهارات وسلوك تتظيم المشاريع ، (Y) إستراتيجيات تتظيم

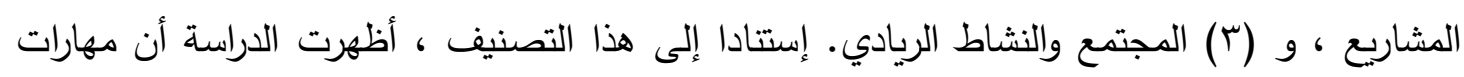

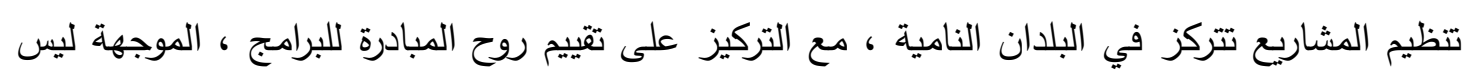
فقط للطلاب الزراعيين في معاهد التعليم العالي ولكن أيضا للنساء والمزارعين الصغار ـ يتم تحليل

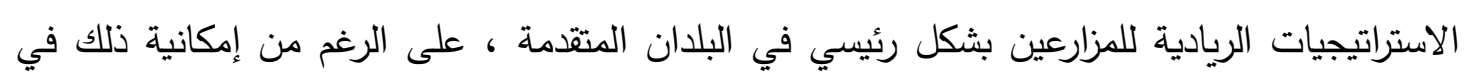

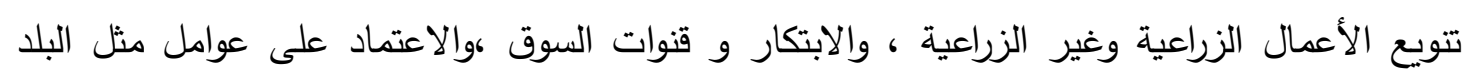

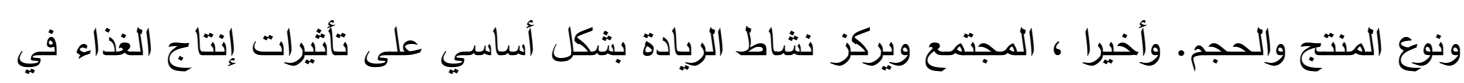

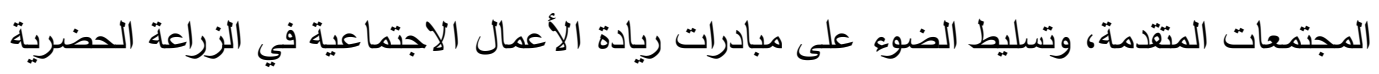

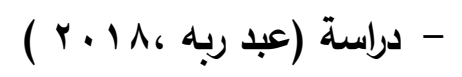

قامت الدراسة على أهمية إدراج ريادة الأعمال فى التعليم كوسيلة للقضاء على البطالة حيث أوضحت

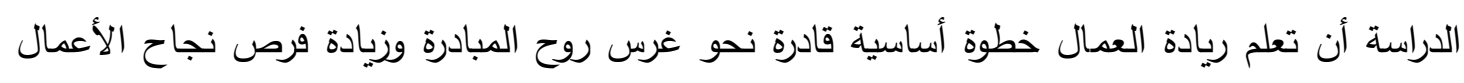

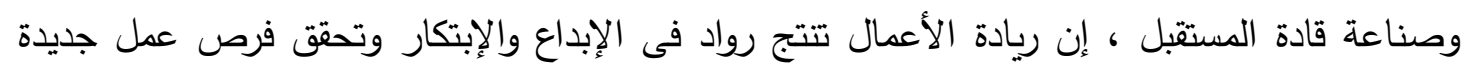
مما يقلل من حجم البطالة وهو يقضى على الفقر والجوع •

(Adel Ben Youssef,2018) دراسة -

بعنوان" ريادة الأعمال والاستدامة: الحاجة إلى حلول مبتكرة ومؤسسية " إلى مناقثة دور الابتكار والجودة المؤسسية لتحقيق الاستدامة حيث يعد من القضايا الهامة التي تعالجها مناقشات التتمية

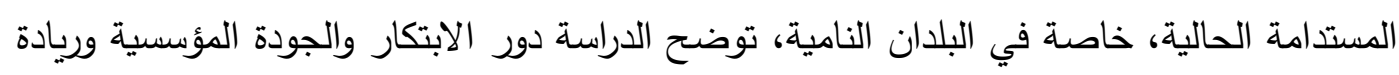

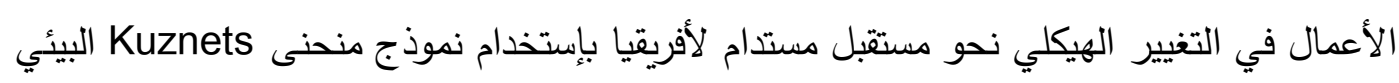
المعدل، بالإضافة إلى أن هذه الدراسة تساهم فى توضيح الظروف التي تسمح للدول الأفريقية بالتحرك نحو اقتصادات أكثر إستدامة. 
وتوصلت الدراسة إلى أن ريادة الأعمال الرسمية وغير الرسمية تؤدي إلى خفض الجودة البيئية

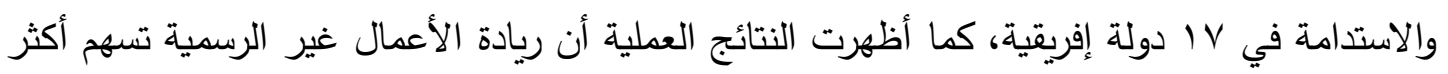
من ريادة الأعمال الرسمية في هذا التدهور البيئي، بالإضافة إلى أن العلاقة بين ريادة الأعمال والتتمية

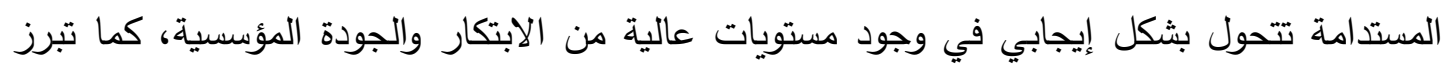
نتائج البحث الدور الهام الذي يلعبه كل من الابتكار والمؤسسات لتحقيق الاستدامة في إفريقيا.) (Jack Mason,2018) دراسه بعنوان" ريادة الأعمال في الخدمات القائمة على المعرفة: الفرص والتحديات لتطوير المشاريع

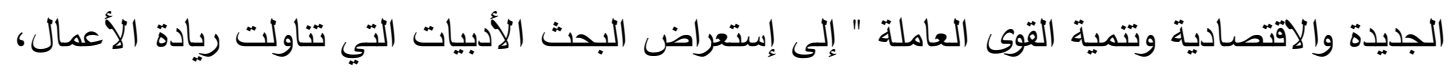

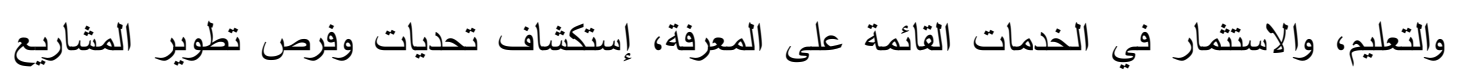
الجديدة المستتدة إلى المعرفة (KBS) وإقتراح سبل البحث والاستثمار في المستقبل لدور ريادة الأعمال في المشاريع الجديدة المستندة إلى المعرفة (KBS).

وقد توصلت الدراسة إلى الأعمال والأنشطة المعروفة بإسم الخدمات المستندة إلى المعرفة

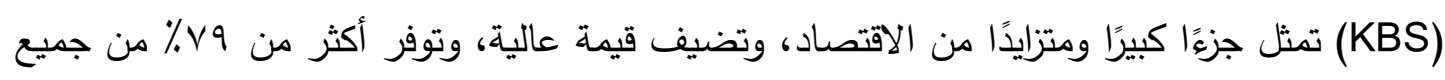
الوظائف غير الزراعية في الولايات المتحدة ، ويككن تصديرها إلى حد كبير ، على الرغم من إتاحة

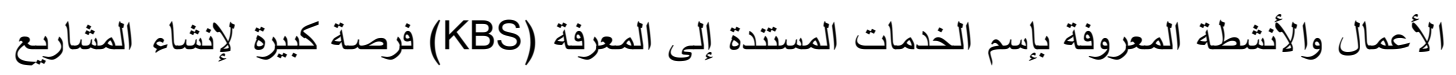
الجديدة وزيادة حجم الاستثمار إلا انه لا يوجد إهتمام بها في مجالات التعليم وتنمية القوى العاملة والبحث العلمي .

(N. Öykü İyigün,2015) دراستة بعنوان" ماذا يمكن أن تفعل ريادة الأعمال لتحقيق التتمية المستدامة؟ منهج قائم على المسؤولية

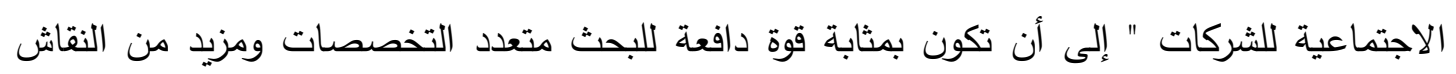
حول، بحث الآثار الدترتبة على المسؤولية الاجتماعية للشركات في التتمية المستدامة، بالإضافة إلى

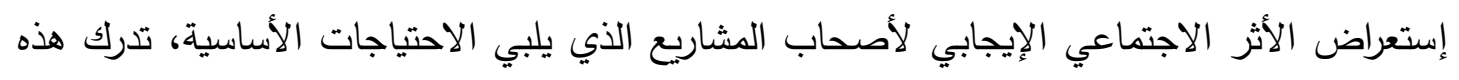

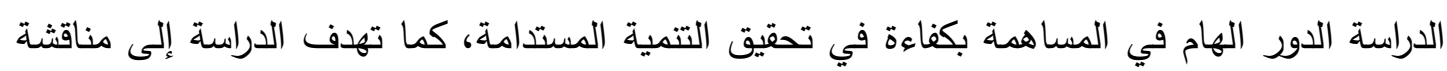

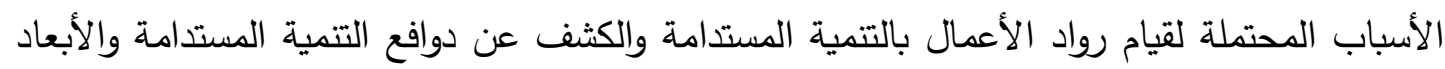
الأساسية في عملية صنع القرار. وتوصلت الدراسة إلى أنه ينظر إلى ريادة الأعمال كبديل للبطالة والفتر الذي يمكن أن يكون

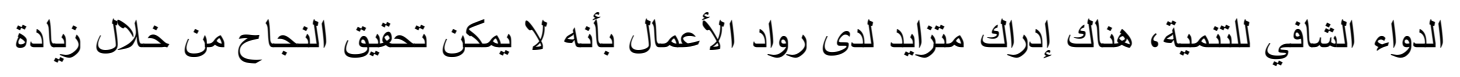




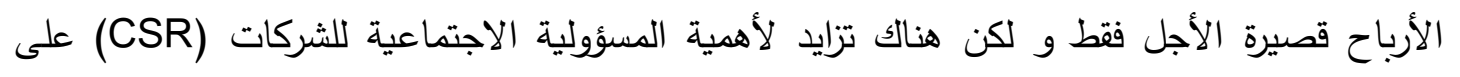

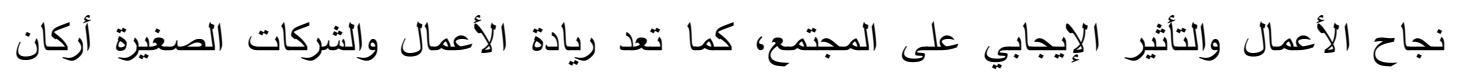

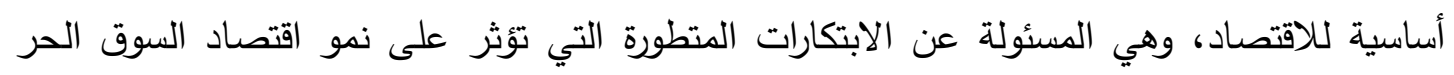
وأدائه العام.

(Zacharoula and Reopoulou, 2014) دراسة -

بعنوان" إستثارات من أجل التتمية المستدامة ، قضايا تبني تكنولوجيا المعلومات ، التسويق وريادة الأعمال في مزارع الثروة الحيوانية " إلى دراسة وتتييم إعتماد الاستشارات من مزارع الثروة الحيوانية ومناقشة الفرص المستقبلية، بالإضافة إلى تقييم مبادرات تمويل مزارع المحاصيل والماشية

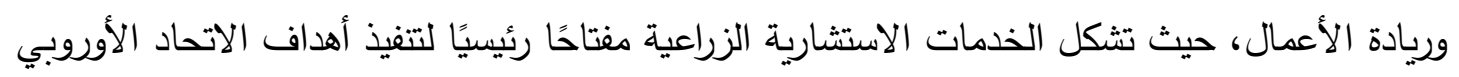

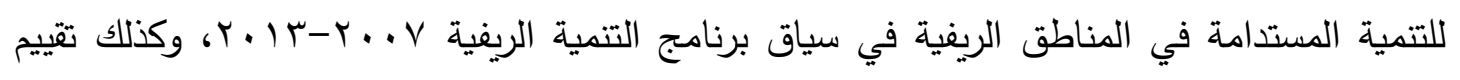
الخدمات الاستشارية والمعلومات موثوقة التي تقدمها للمزارعين اليونانيين فيما يتعلق بتبني تكنولوجيا المعلومات والأدوات الإكترونية المبتكرة، وتسويق المنتجات الزراعية ومعالجتها، والمنتجات الزراعية المعتمدة من (ISO) ، وتحديث الحيازات الزراعية ، إلخ، بالإضافة إلى بحث الفرص لمشاركة

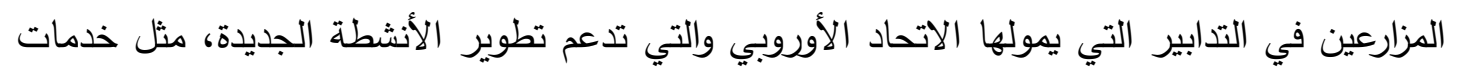

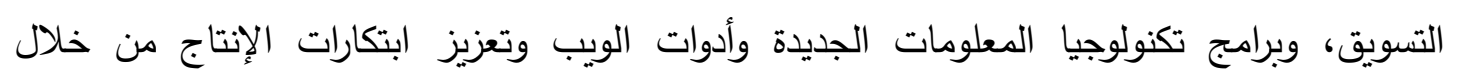
الاستثمارات الجديدة.

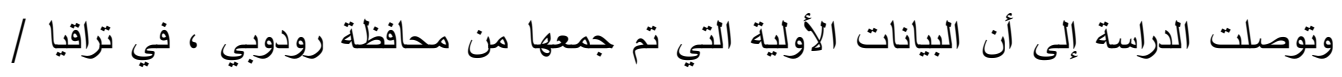

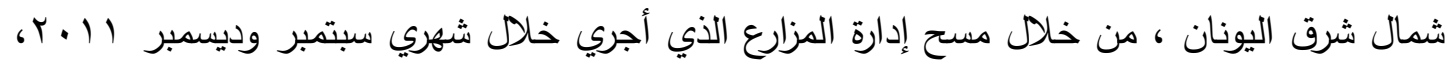

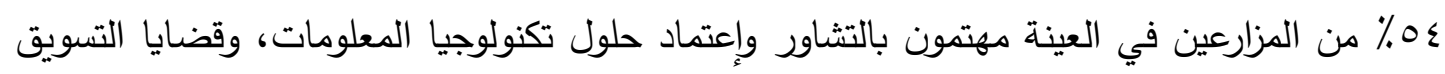

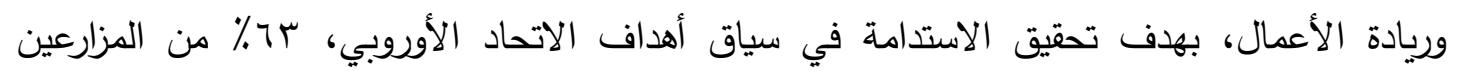

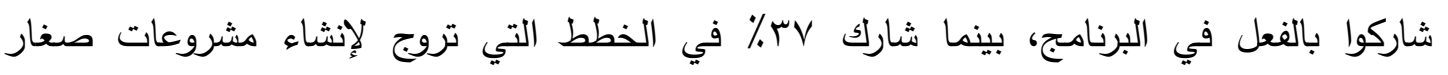

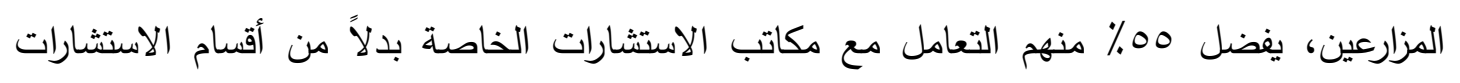
الحكومية.

كما أوضحت نتائج الدراسة أن مكاتب الاستشارات الخاصة تفيد المزارعين الذين يعتبرونهم

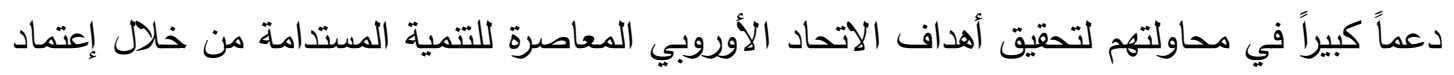

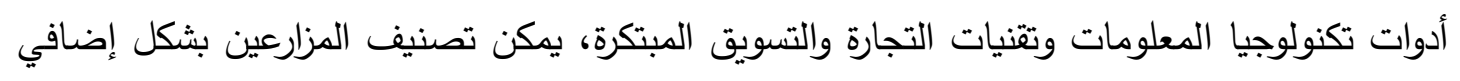

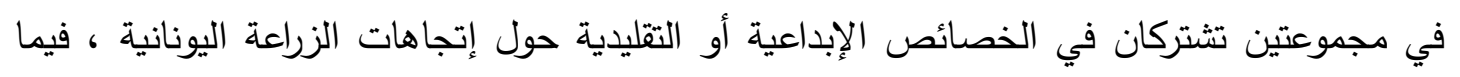
يتعلق بخصائصهما الاجتماعية.

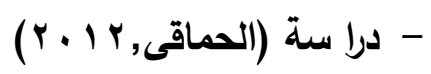




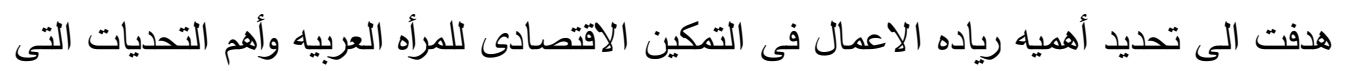

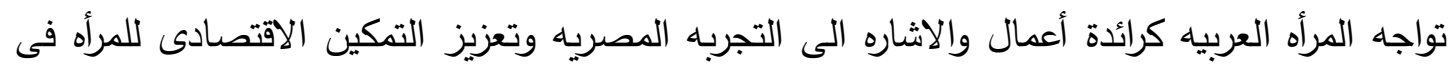

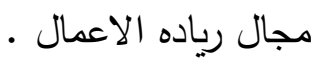
وقد توصلت الدراسه الى ضروره تثجيع المرأه العربيه على الانضمام للاتحادات العماليه والتجاريه

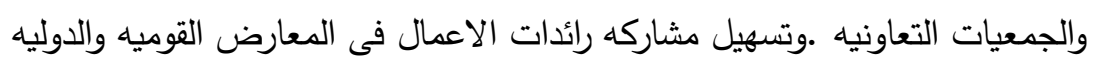

(R. Cervelló-Royo,2019) دراستة

وآخرون بعنوان" التتمية المستدامة والعوامل الاقتصادية والمالية التي تؤثر على ريادة الأعمال "

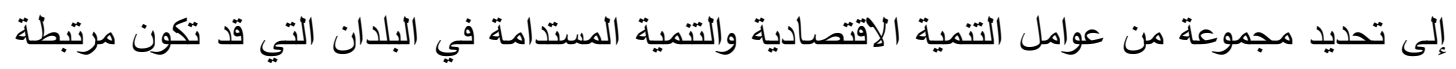

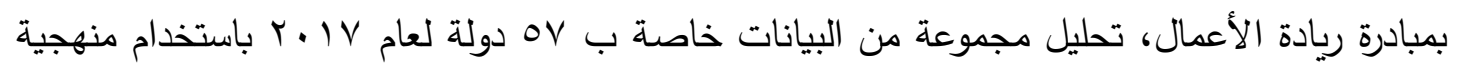

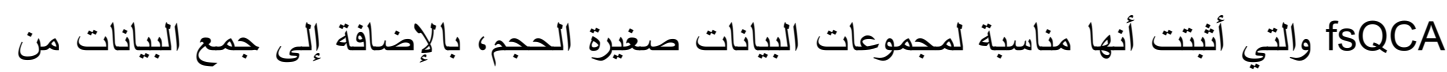

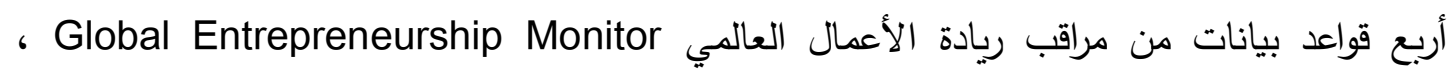

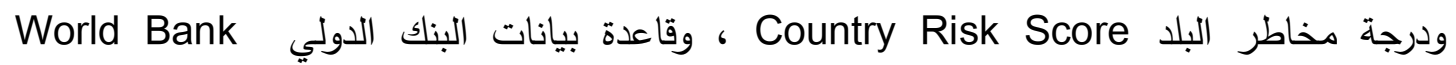

Sustainable Development Goals Index ومؤشر أهداف التتمية السستدامة Database وتوصلت الدراسة إلى أن عوامل التتمية الاقتصادية والتتمية المستدامة المؤثرة على مبادرات

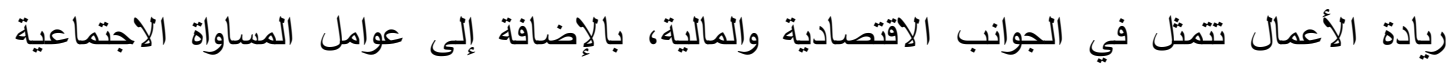
والتعليم والإنتاج المسئول ومؤشرات الابتكار والبنية التحتية.

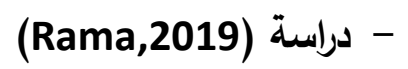

هذه الدراسة عن العلاقة بين ريادة الاعمال والمدن الذكية حيث المدينة الذكية هي مدينة ريادة

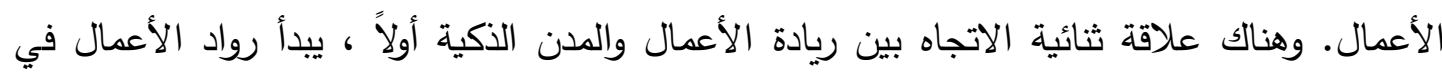

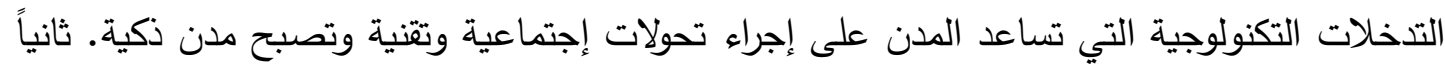

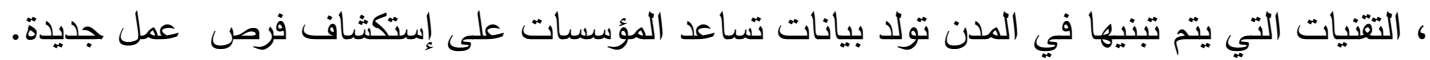

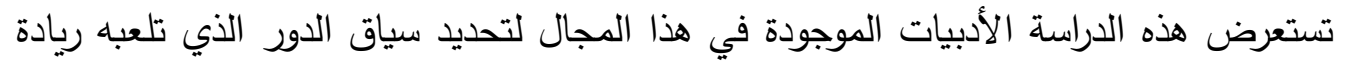

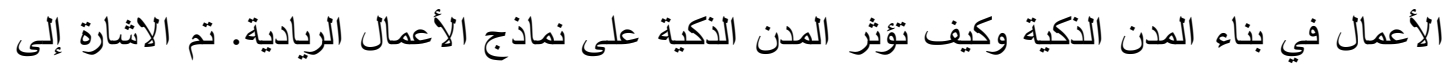

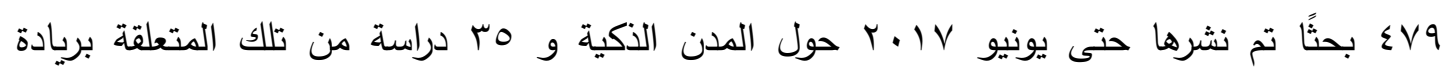

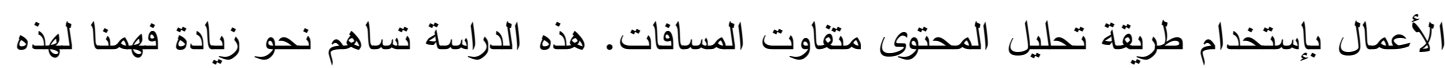

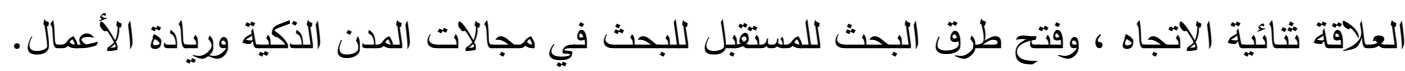

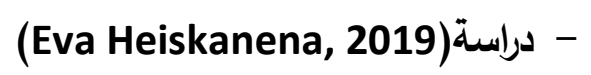

هذه الدراسة عن تعزيز الطاقة المستدامة هل تساعد ريادة الاعمال المؤسسية وقد وصفت

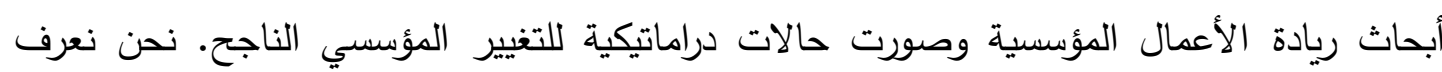

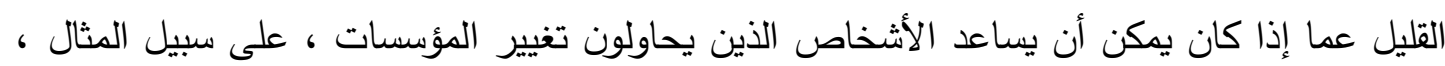

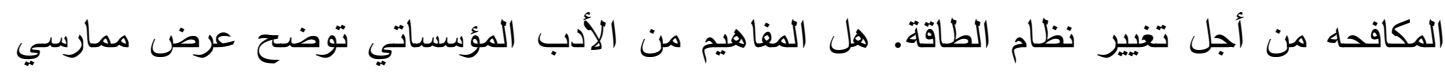


الطاقة المستدامة رؤى حول الجوانب السياسية لعمله؟ والعكس بالعكس: هل الممارسين لديهم رؤى مفيدة حول إمكانات وحدود الوكالة في التغيير المؤسسي؟ هذه الدراسة تساهم فى حل هذه الأسئلة من خلال التحقيق التعاوني مع المنظمات التابعة للحكومة وتثير النتائج إلى أن المفاهيم من روح المبادرة المؤسسية حيث تعمل الأدبيات على جعل الكفاءات الضمنية للممارسين واضحة ، وبالتالي موضوعًا مشروعًا للتتمية التنظيمية والتعلم المشترك حول الجوانب السياسية لتغيير أنظمة الطاقة. ويبدو أن روح المبادرة المؤسية تتطلب شكلاً من أشكال التظيم يجمع بين المسح البيئي والاستراتيجية الكبرى والتحركات التكتيكية اليومية على الأرض.

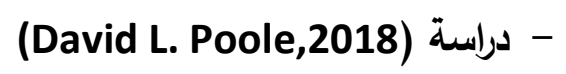

بعنوان" ريادة الأعمال والثركات الصغيرة والمتوسطة في الاقتصادات النامية " إلى أن تحليل

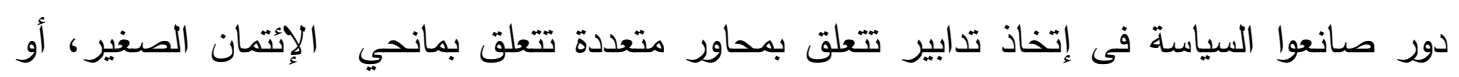
مستشارين إداريين، أو منظمات غير حكومية أو الاقتصاديين من مختلف البقاع وتوصلت الدراسة إلى بلى إلى

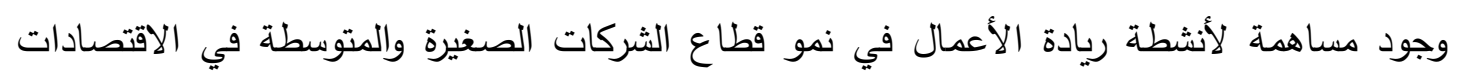
النامية. والقضاء على البطاله.

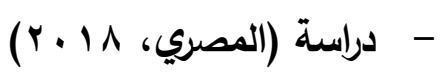

قامت الدراسة على دور حاضنات الأعمال والحدائق التكنولوجية فى دعم ريادة الأعمال وأصحاب المشروعات الصغيرة ومدى مساهمتها فى تكوين الثروة وزيادة معدل نمو الدخل المحلى الاجمالى ودعم الاقتصاد فى الأردن • وأوضحت الدراسة دور ريادة الأعمال فى القضاء على البطالة وخفض نسبتها وذلك بتوفير فرص عمل للخريجين وتتمية ودعم رواد الأعمال .

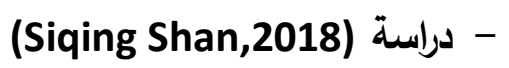

وآخرون بعنوان" تقييم مساهمة ريادة الأعمال التكنولوجية في الصين على التتمية الاجتماعية

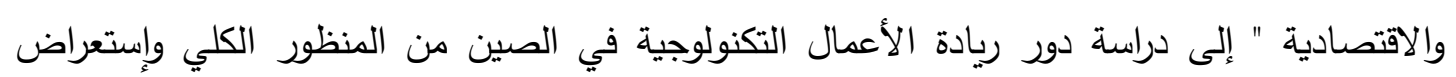
الإطار النظري لها والأهمية العملية للتمية الاجتماعية والاقتصادية، بالإضافة إلى تقييم مساهمات ريادة الأعمال التكنولوجية في التتمية الاقتصادية والتتمية المستدامة. توصلت الدراسة إلى أن تطور الاقتصادات الناشئة يعتبر إتجاه مهم كمحرك للنمو الاقتصادي العالمي وقد تبنت الصين مشروعات ريادة الأعمال التكنولوجية كإستراتيجية وطنية للتتمية الاقتصادية المستقبلية، تزايد عدد المؤسسات التكنولوجية مع إرتفاع مساهماتها في زيادة قيمة الإنتاج والصادرات لئهن

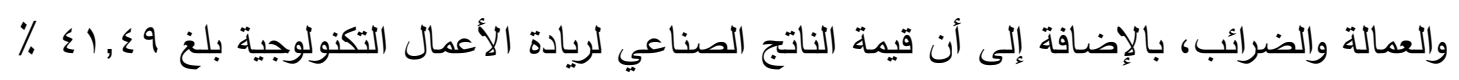

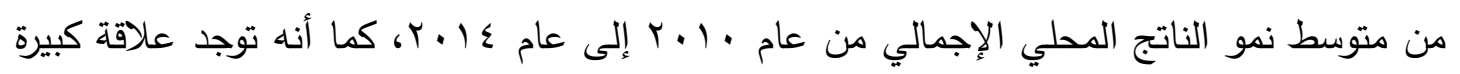
بين ريادة الأعمال التكنولوجية والنمو الاقتصادي مع معامل الارتباط وقد إتضح من النتائج أن ريادة

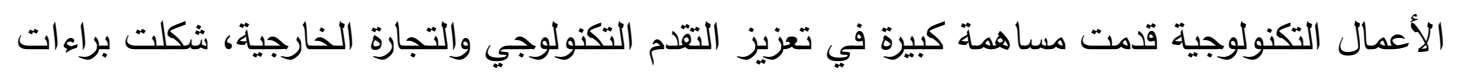
الاختراع التي إبتكرها رواد الأعمال حوالي ال ا ٪ من براءات الاختراع المحلية، بلغت القيمة الإجمالية 


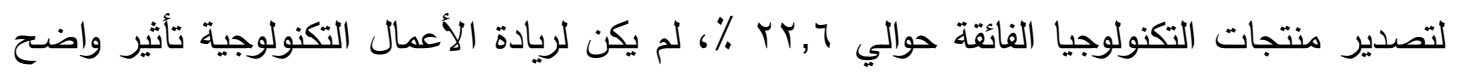

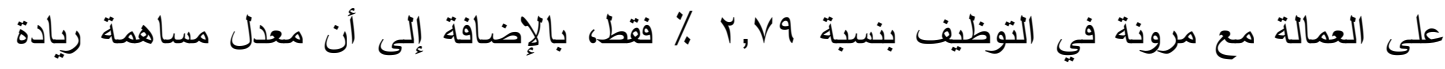

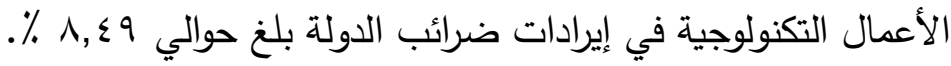

- دراسة(C.Makropoulosa,2018)

هذه الدراسة عن الصرف الصحى كخيار لإعادة إستخدام المياه يدعم الاقتصاد الدائرى وتقديم

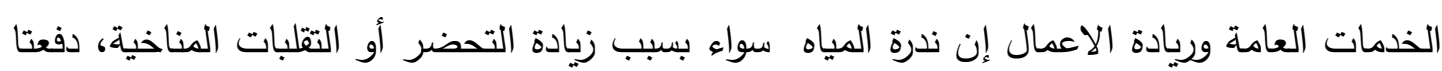

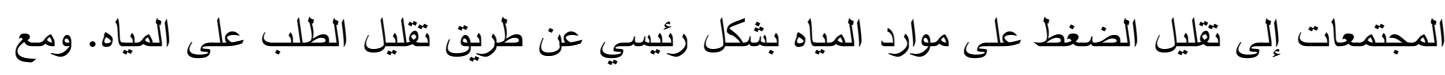

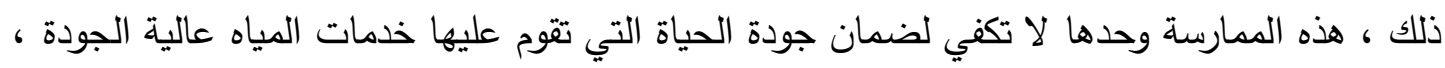

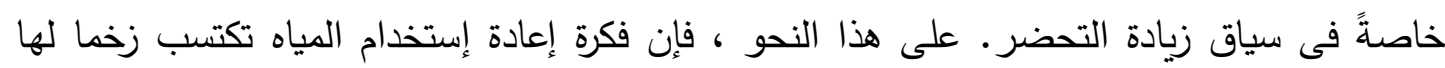

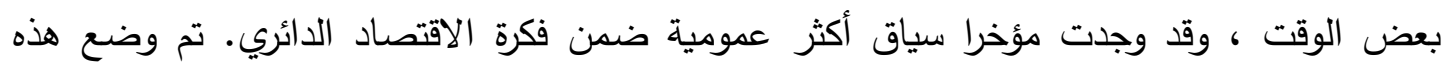

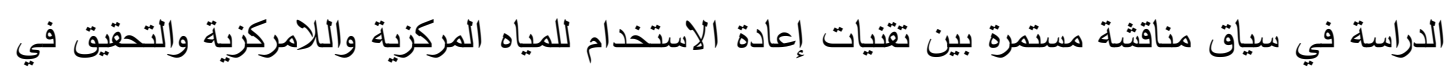
المقايضات بين الكفاءة والقدرة الاقتصادية لإعادة الاستخدام في جداول مختلفة. على وجه التحديد ،

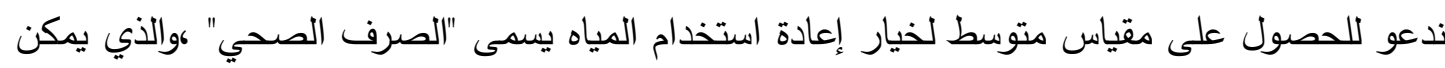

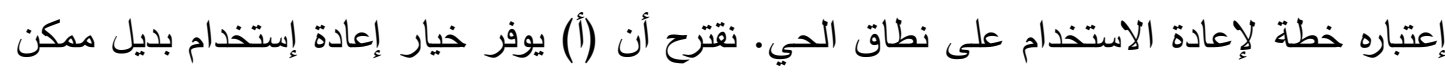

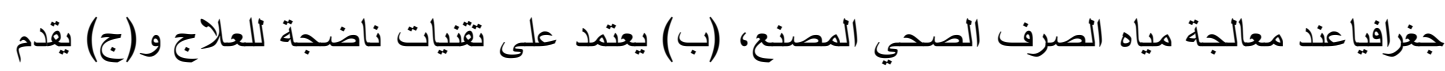

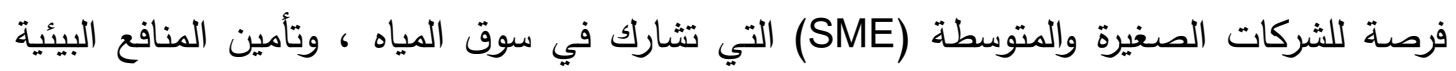

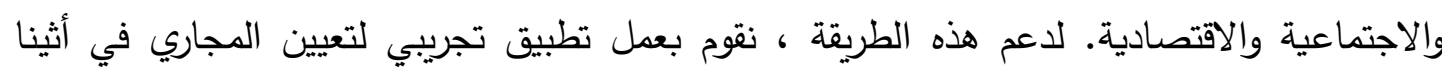
،اليونان. يقوم بدمج نظامين فرعيين: وحدة المعالجة المعبأة والبنية التحتية لتكنولوجيا المعلومات

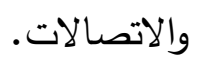

\section{- دراسة(Suyash Jolly,2016)}

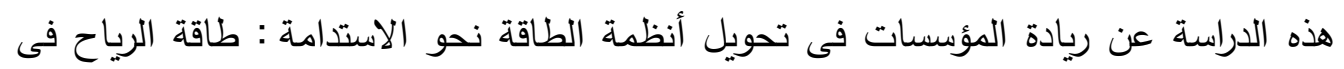

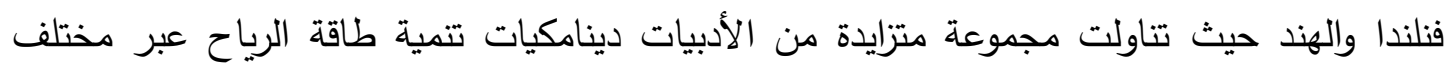

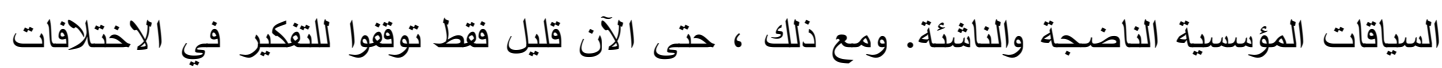

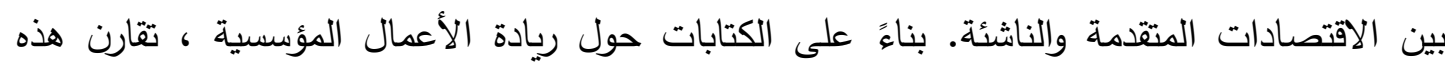

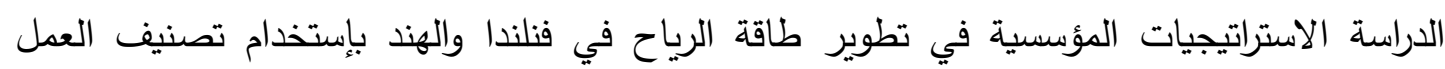

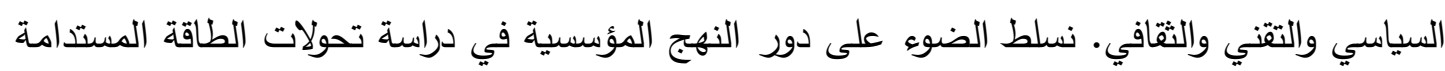

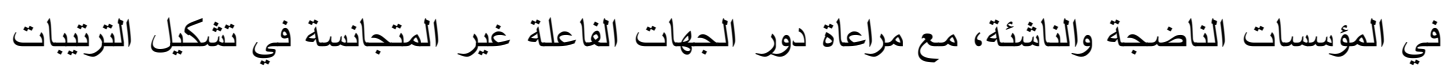

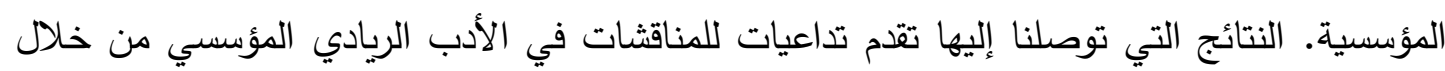

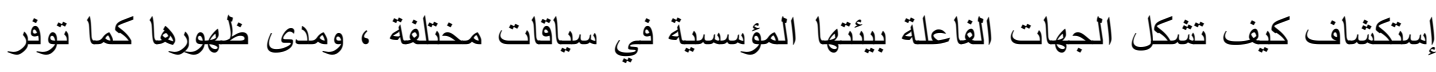

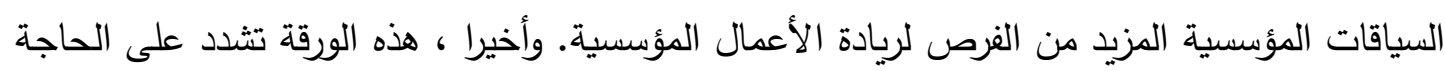


إلى تطوير رؤى ثاقبة للظروف المواتية لريادة المؤسسات الجماعية الناجحة وتطوير نماذج من الاستراتيجيات المؤسسية القابلة للتعميم عبر السياقات المؤسسية الناضجة والناشئة.

(NoratRoig , 2015) دراسة -

يبحث هذا البحث في العلاقة بين النمو وإستخدام البنية التحتية الداعمة للابتكار وريادة الأعمال. وتتناول الدراسة ثلاثة أنواع من البنية التحتية الداعمة: الحاضنات ومراكز التكنولوجيا والجامعات. بإستخدام التحليل المقارن النوعي الدقيق تختبر الدراسة وجود هذه العلاقات بإستخدام البيانات التجريبية من عينة (ن = V • () من الشركات المبتكرة. تظهر النتائج أن الجمع بين إستخدام الحاضنات ومراكز التكنولوجيا والجامعات يمكن أن يؤثر إيجابيا على إبتكار الشباب ونمو الشركات.

\section{- دراسة (Mihaela Kardos,2012) -}

بعنوان" العلاقة بين ريادة الأعمال والابتكار والتتمية المستدامة ، البحث في دول الاتحاد الأوروبي " إلى ربط ريادة الأعمال المستدامة والتنمية المستدامة من منظورات الإطار المفاهيمي في الأدبيات والبحث في دول الاتحاد الأوروبي، حيث تعتبر العلاقة بين ريادة الأعمال والابتكار والتتمية المستدامة موضوع إهتمام كبير في الوقت الحاضر ، حيث يبحث المجتمع عن حلول تؤدي إلى التتمية المستدامة، بالإضافة إلى توضيح أهمية البحث خاصة لكل من الباحثين وواضعي السياسات ويوفر فرصًا للدراسات المستقبلية حول هذا الموضوع. وتوصلت الدراسة إلى أن ريادة الأعمال المستدامة يتم النظر إليها من خلال منظور الشركات

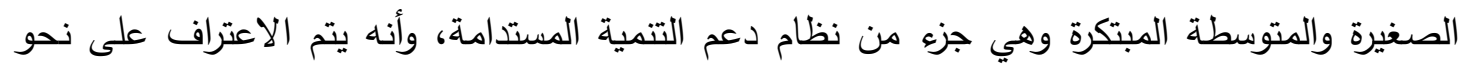
متزايد بمشاريع ريادة الأعمال كقوة دافعة للابتكار والقدرة التنافسية، بإعتبارها واحدة من مفاتيح تحقيق دمثي التنمية المستدامة.

(Desirée F. Pacheco, 2005) دراسة -

وآخرون بعنوان" دور عامل ريادة الأعمال في تنمية السياحة المستدامة " إلى تقييم دور ريادة

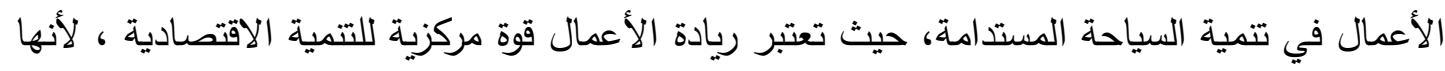
Söderslätt تولد النمو وتعمل كوسيلة للابتكار والتغيير، عرض نتائج تحليل SWOT لتطوير منطقيل لريادة الأعمال السياحية، والذي يعطي نظرة عامة على وضعهم الحالي في مجال الأعمال الحرة. وتوصلت الدراسة إلى أن السياحة هي أحد القطاعات الاقتصادية التي يحتاج فيها قطاع الأعمال إلى درجة كبيرة من المشاركة، هناك حاجة إلى تتويع المنتجات والخدمات السياحية لمواجهة الطلب المتزايد على أنواع جديدة من الاحتياجات السياحية وهي تتضمن مزيد من فرص السيح السياحة المستدامة، وقد تم إقتراح العديد من التوصيات للتغلب على العقبات التي تحول دون تتمية ريادة

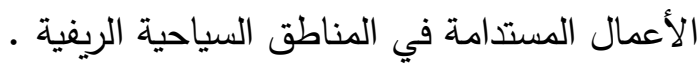

(Eriksson,2013 ) دراسة - 
بفحص تجريبى للتخفيف من حدة المناخ فى الإنتاج الزراعى بإستخدام منهجية لششروع يديره

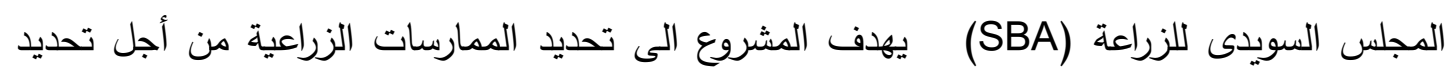

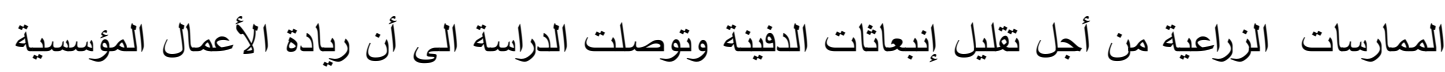

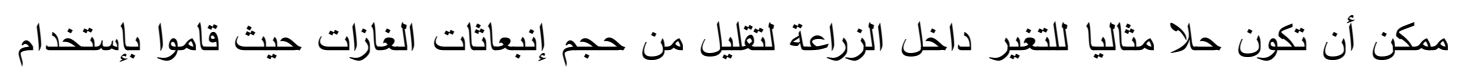

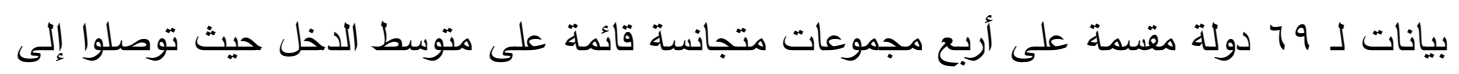
أن ريادة الأعمال تساهم بثكل إيجابى فى تحسين جودة البيئة .

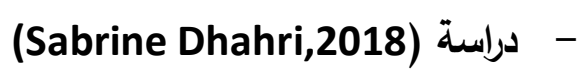

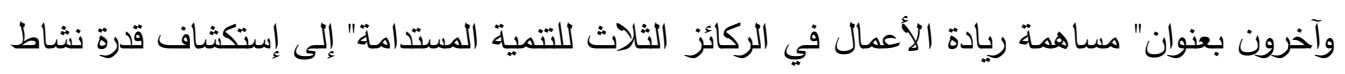

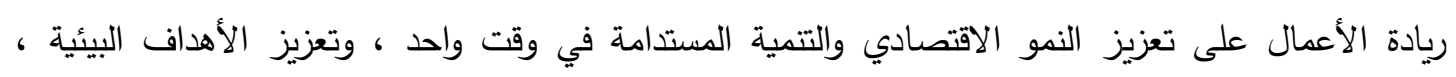

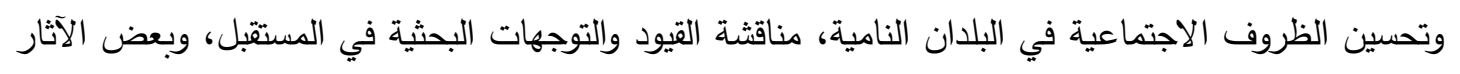

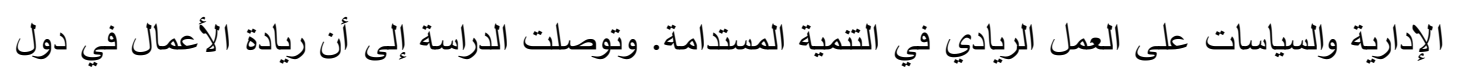

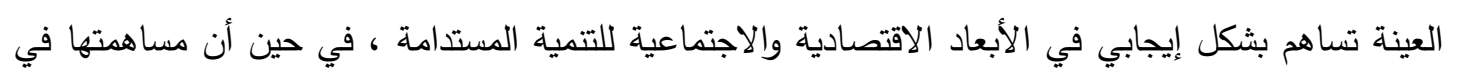

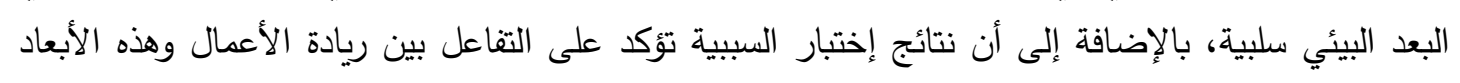

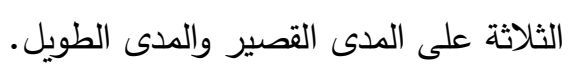

وأثبتت الدراسة أن هناك أثر ايجابى للعمل الجماعى من قبل الجمعيات التجارية على البيئة

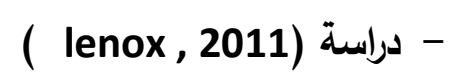

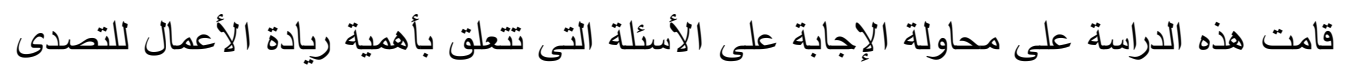

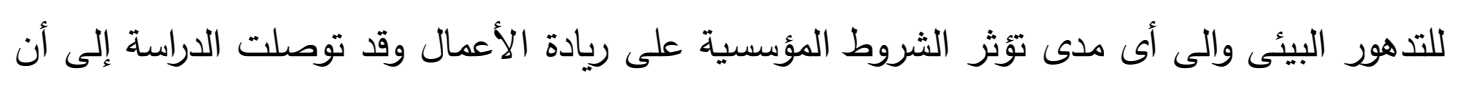

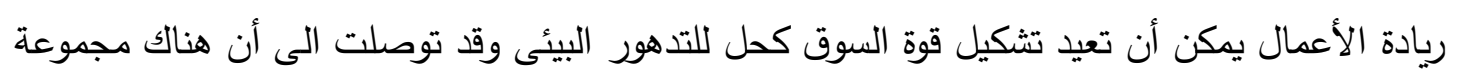

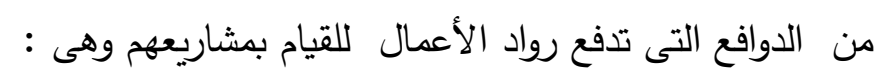

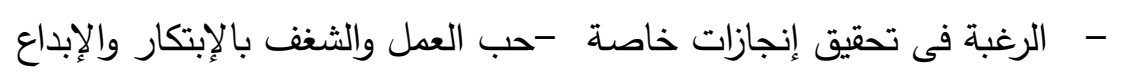

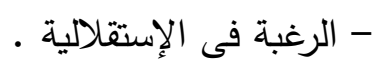

\section{- دراسة (Daniela Stefanescu,2012)}

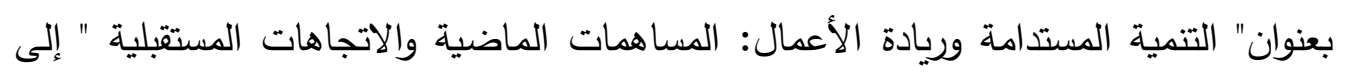

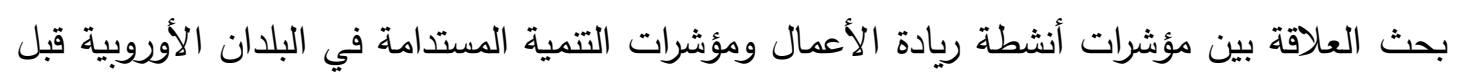

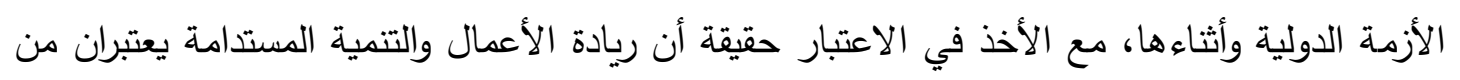

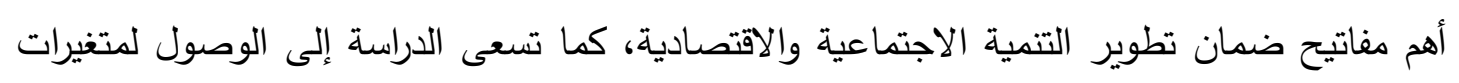

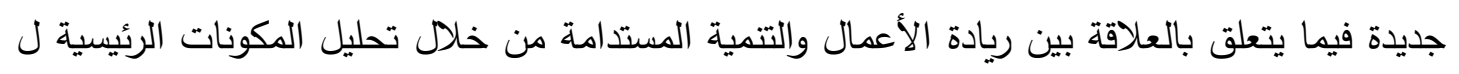

$$
\text { بإستخدام حزمة برمجيات (PCA) }
$$

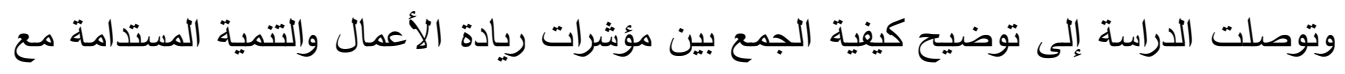
بعضها البعض، وكذلك توزيع الدول الأوروبية على أساس عناصر جديدة ناتجة عن إستخدام PCA، 
وقد إستندت نتائج البحث إلى البيانات والمعلومات التي تم جمعها من قواعد بيانات Eurostat و .Global Entrepreneurship Monitor

(Gheorghe Zaman,2012) دراسة -

بعنوان" الجوانب البارزة للتنمية المستدامة والتحديات التنافسية لريادة الأعمال في رومانيا " إلى تسليط الضوء على الخصائص الرئيسية لأصحاب المشاريع في رومانيا من وجهة النظر الديموغرافية والاقتصادية والاجتماعية والعمر ومهارات العمل والتعليم والجنس في المناطق الحضرية والريفية و

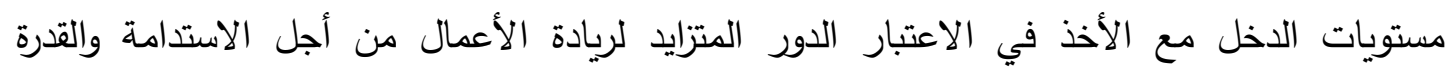

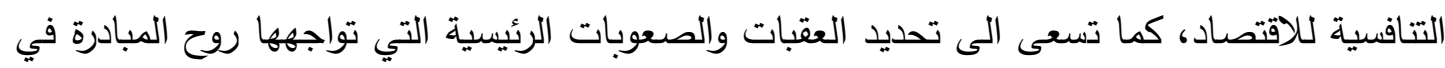
رومانيا بالإضافة إلى إيجاد الحلول لحلها عن طريق سياسات وأدوات وآليات اقتصادية ومالية مناسبة إستتادا إلى مجموعة من المؤشرات المحددة.

وتوصلت الدراسة إلى انه تم الكثف عن أهمية تعزيز التوجه نحو أنشطة ريادة الأعمال فضـلاً

عن أهمية الدعم المالي للشركات الصغيرة والمتوسطة.

(Desirée F. Pacheco, 2010) دراسة -

وآخرون بعنوان" ريادة الأعمال وخلق فرص للتنمية المستدامة " إلى تقديم مجموعة متتوعة من

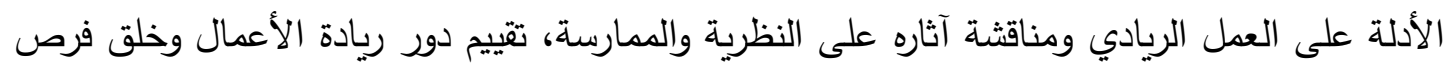
للتتمية المستدامة.

وتوصلت الدراسة إلى ان كفاءة ريادة الأعمال تعتمد على طبيعة حوافز السوق، على الرغم من

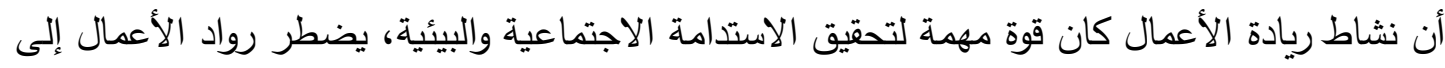

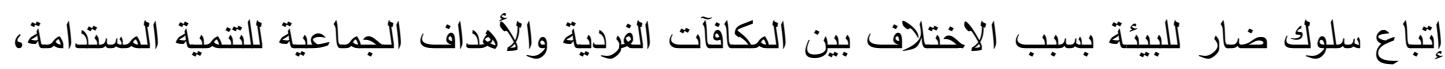
وأنه يمكن لرجال الأعمال تغيير أو إنشاء القواعد المؤسسية وحقوق الملكية والتشريعات التي تحدد بلتئل

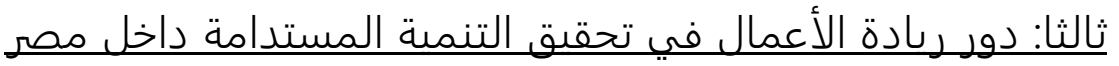

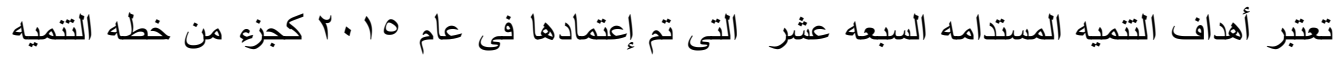

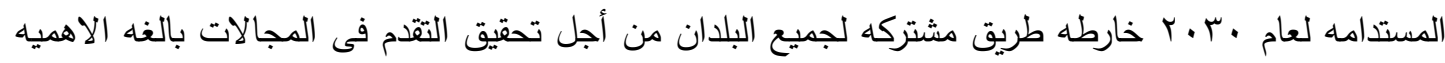
للبشر ولابد أن تعمل جميع البلدان ومن بينها مصر لتحقيق أهداف التتميه المستدامه. ونجد أن مصر قد أتبعت برنامج حكومى لتحقيق هذه الاهداف أطلق عليه "مصر تنطلق"

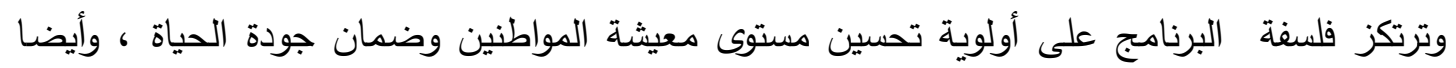
بناء الإنسان المصرى ، إيمانا بأنه لا تنمية دون مواطن متمتع بمستوى معيشة وخدمات ذات جودة

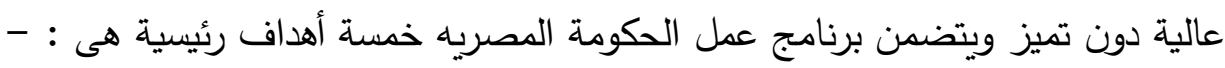
- - مماية الأمن القومى وسياسة مصر الخارجية . - - بناء الإنسان المصرى 
- - التتمية الإقتصادية ورفع كفاءة الأداء الحكومى -

- - النهوض بمستويات التشغيل

- تحسين مستوى معيشة المواطن المصرى (www.cabinet.gove,eg)

ويركز الهدف الإستراتيجى الخامس على تحسين مستوى معيشة المواطن المصرى من خلال

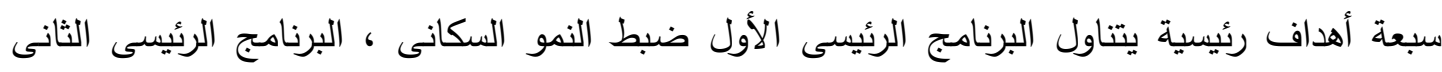

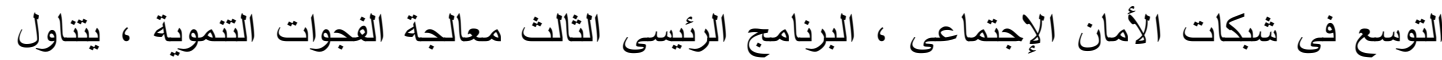

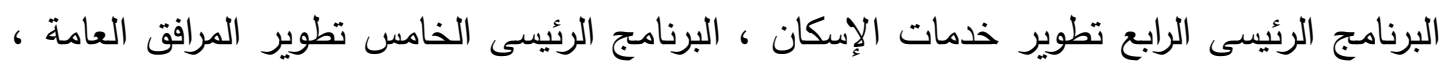

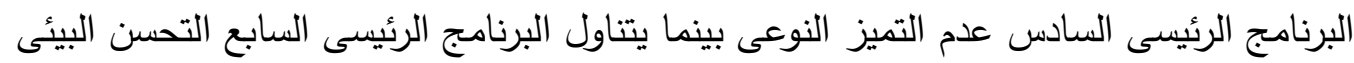

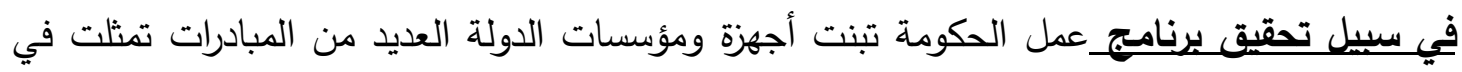
الآتي:

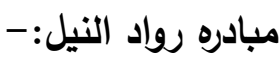

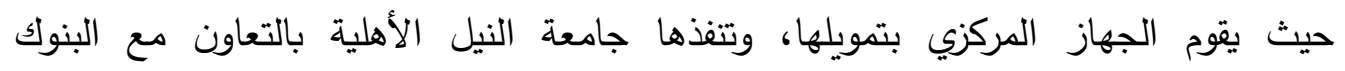
والجامعات، والعديد من الجهات المحلية والدولية، لاعم ريادة الأعمال والمشروعات الصغيرة

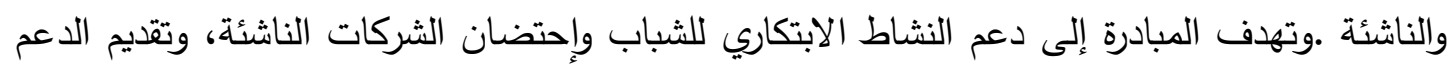

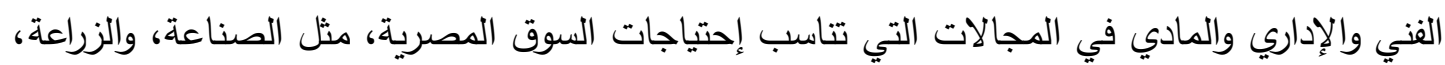

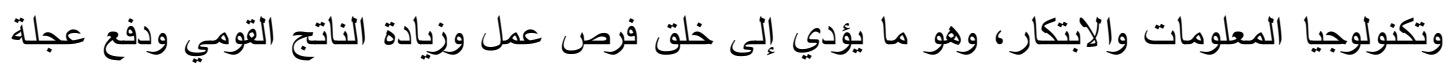

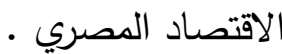

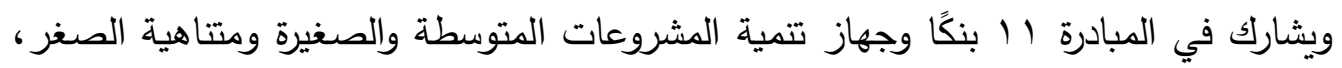

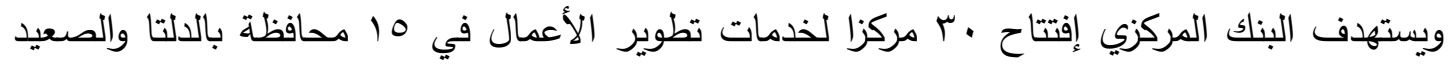

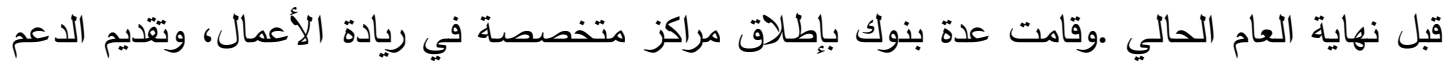
لأصحاب المشروعات الصغيرة والمتوسطة داخل فروعها، وهي بنك القاهره , بنكا التجارى وفا, البنك الاهلى المصرى,المصرف المتحد, بنك QNB,بنك التتميه الصناعيه ,بنك التعمير والاسكان, البنك

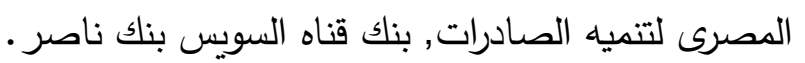

مبادرة إنشاء نوادي ريادة الأعمال

تم إطلاق مبادرة أكاديمية البحث العلمي والتكنولوجيا لإنشاء نوادي ريادة الأعمال بالجامعات

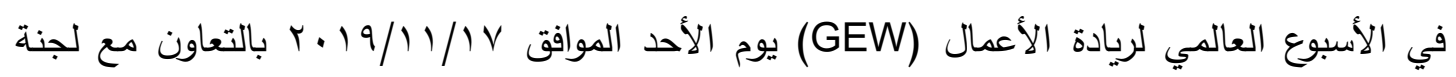

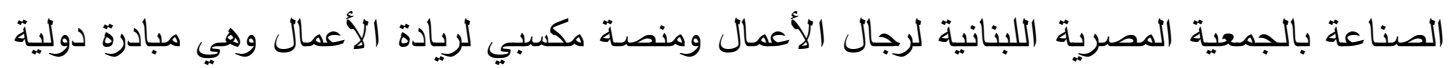
تهدف لتعريف الثباب في القارات الست بموضوع ريادة الأعمال.

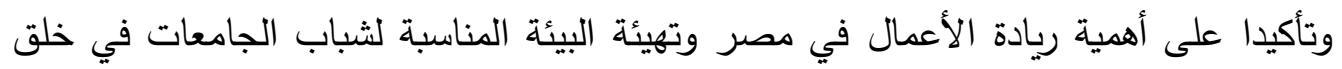

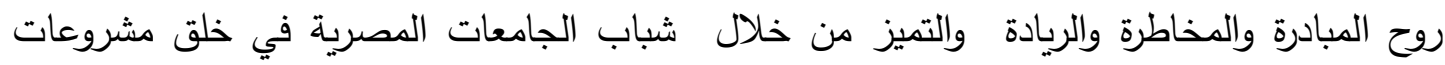

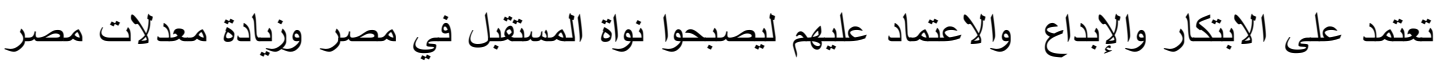


في تعميق التصنيع المحلي، تم إنثاء هب نادي ريادة أعمال بتمويل فني ومالي وتوفير كافة أوجه الدعم لهم من خلال الأكاديمية.

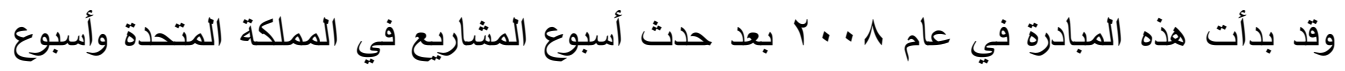

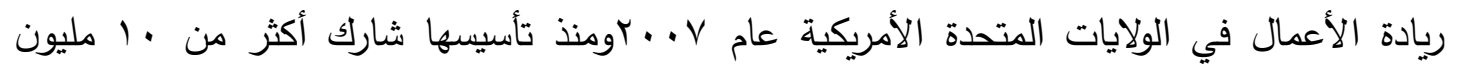

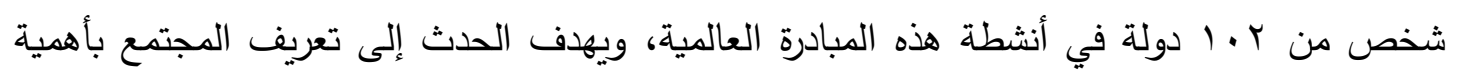

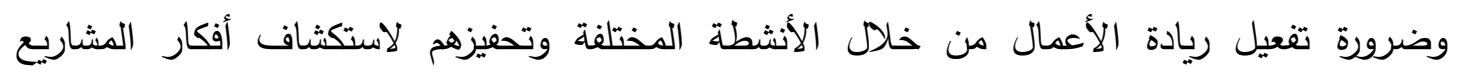
الخاصة بهم.

\section{مبادرة دعم المشروعات الصفيرة والمتوسطة}

أطلق البنك المركزي المصري العديد من المبادرات لإتاحة التمويل اللازم للشركات متتاهية

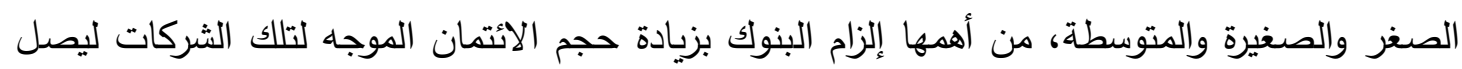

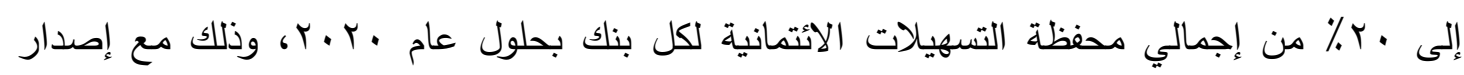

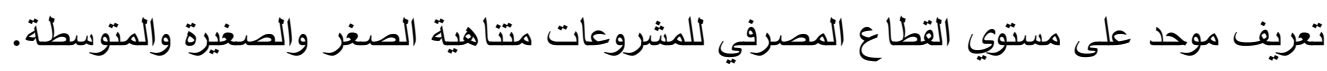

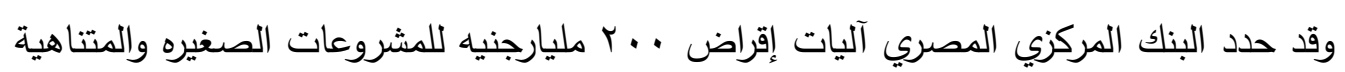

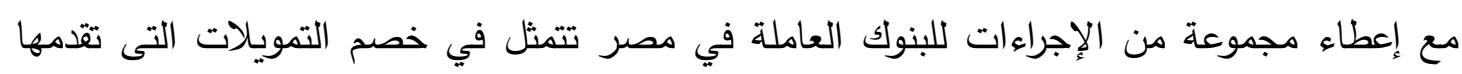

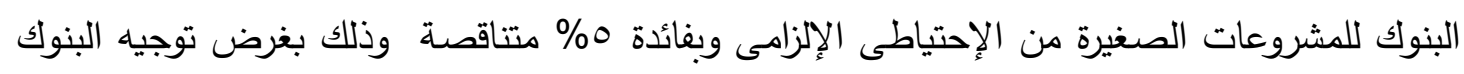

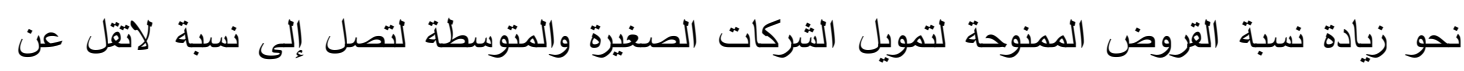

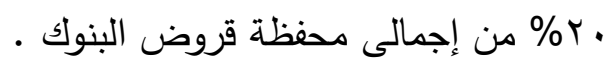

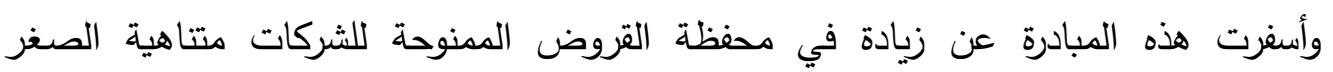

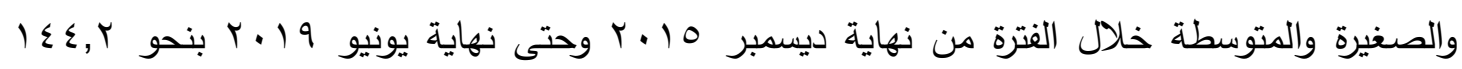

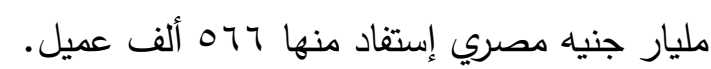

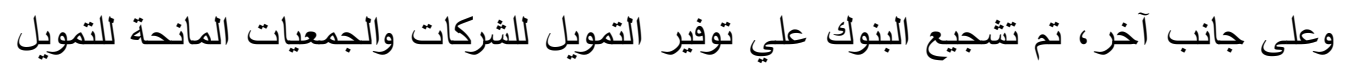

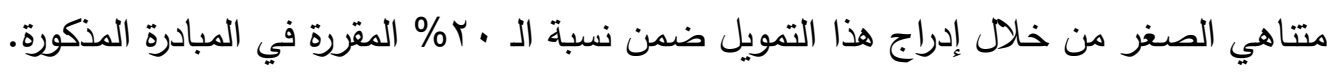

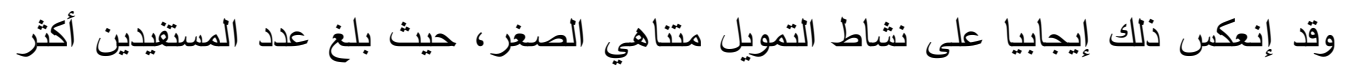

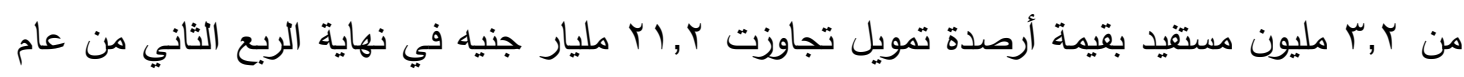

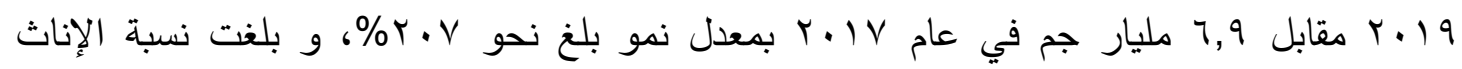

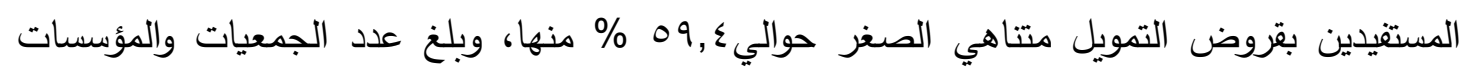

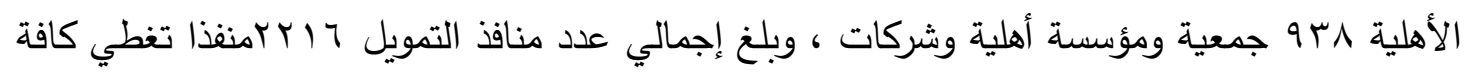

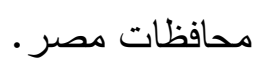

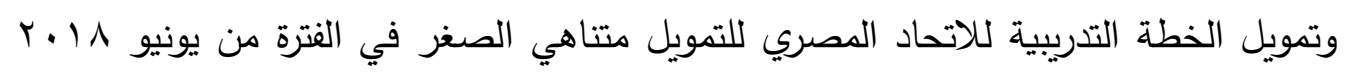

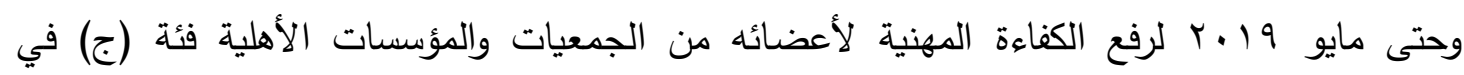




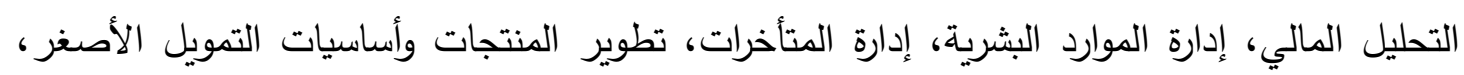

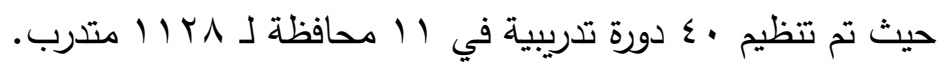

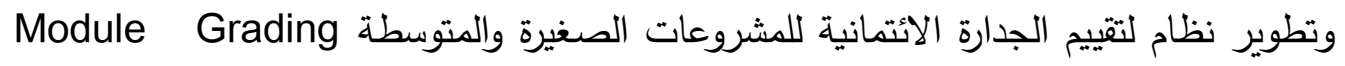

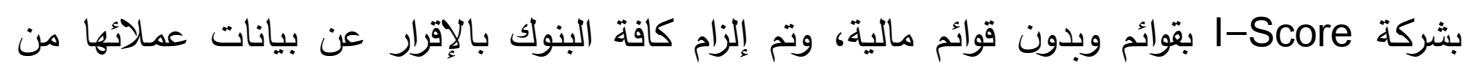
المشروعات الصغيرة والمتوسطة للشركة بغرض تكوين قاعدة بيانات متكاملة لإستخراج تقارير فعلية عن السوق الصصري وكذا مؤشرات كلية على مستوي الصناعات، المناطق الجغرافية، وإثترك في النظام حتى الآن 11 1 بنك.

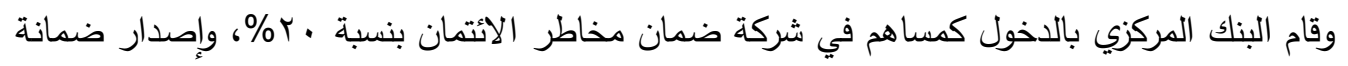

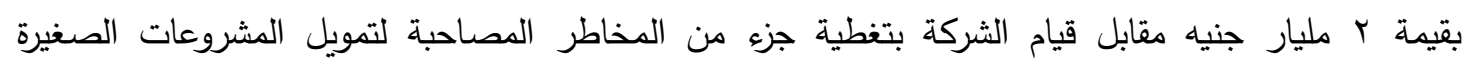

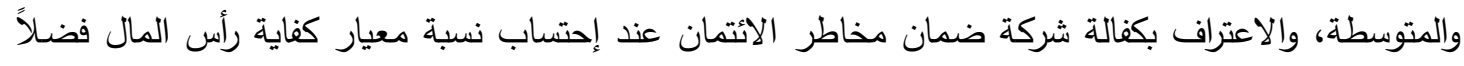
عن الاعتداد بضمان الثركة عند تكوين المخصصات لتشجيع البنوك علي تمويل المشروعات الصغيرة

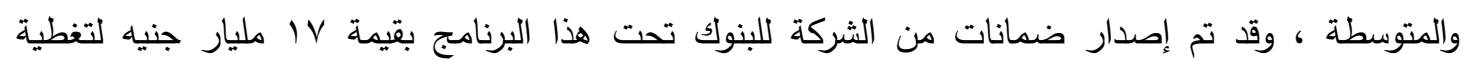

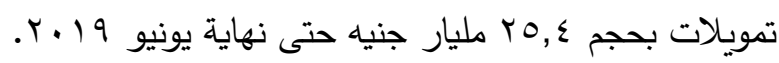

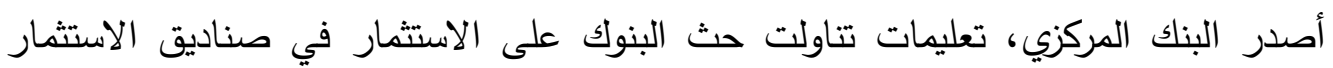

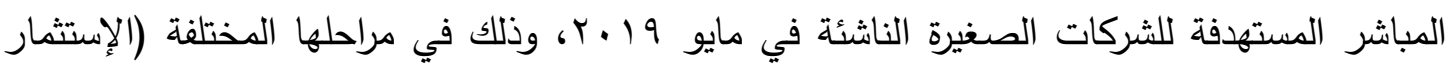

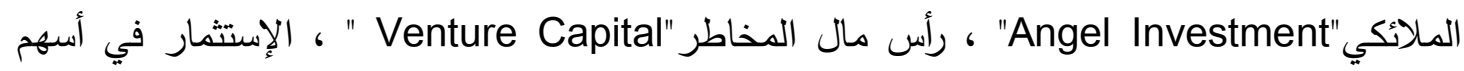

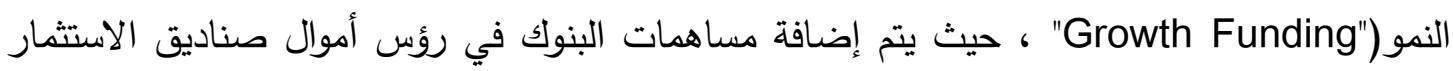

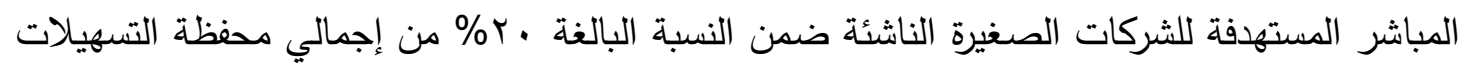
الايتمانية للبنك السالف ذكرها.

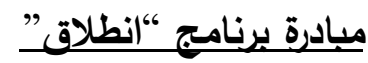

برنامج" إنطلاق" برنامج حكومي في مصر يدير IV حاضنة تكنولوجية وصناعية، يهدف إلي

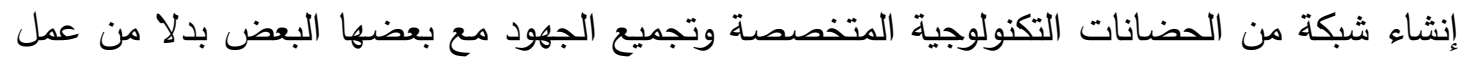

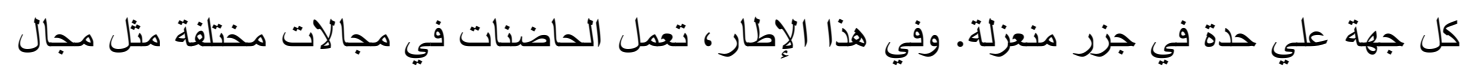

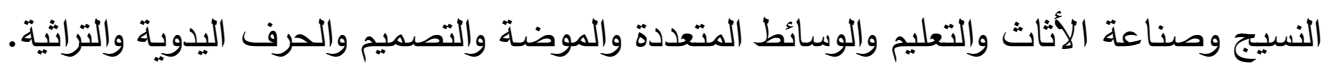

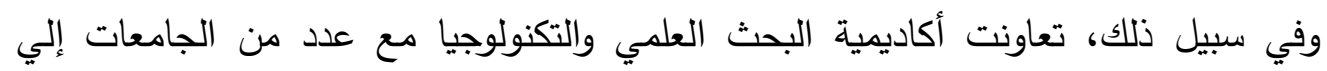

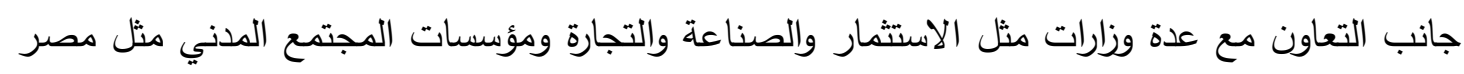

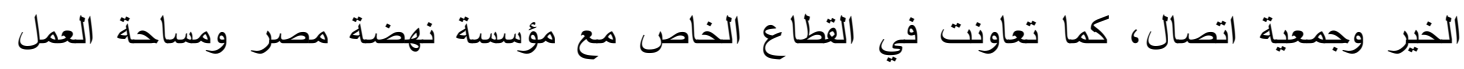

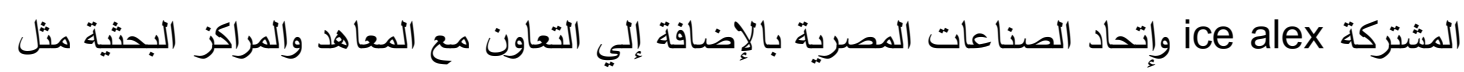

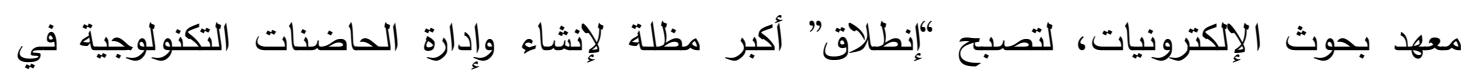

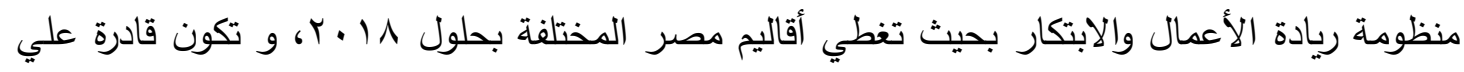

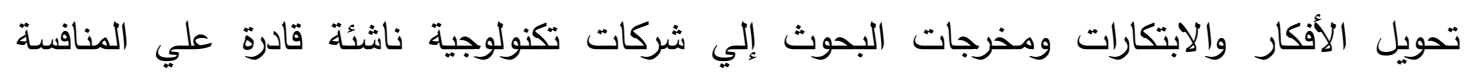


الاقتصادية والتكنولوجية وتحظى منتجاتها بقدرات تنافسية تحقيقًا لهدف الاقتصاد المعرفي وتتمية الشباب

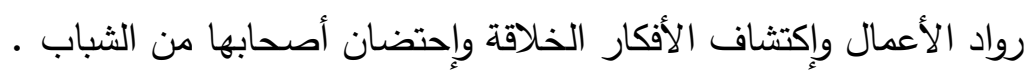

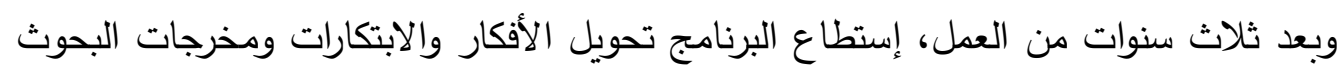
إلى شركات تكنولوجية ناشئة قادرة على المنافسة الإقتصادية والتكنولوجية، تحظى منتجاتها بقدرة تتافسية تحقيقا لهدف الاقتصاد المعرفي. تثير النتائج على الأرض إلى إنثاء IV حاضنة دعمت بات شركة ناشئة بتمويل حكومي يتجاوز مليوني دولار . مبادرة برنامج الشمول المالي

أصدر البنك المركزي، تعريف الثركات والمنشآت المملوكة للمرأة أو التي تُدار من قبلها: لأغراض قياس الثمول المالي للمرأة بالنسبة للشركات متتاهية الصغر والصغيرة والمتوسطة، وذلك على النحو التالي، وفقا للملكية (رأس المال): إمتلاك نسبة لا تقل عن إه ه م من رأس مال الثركة لامرأة واحدة ، ووفقا للملكية (رأس المال) والإدارة: إمتلاك نسبة لا تقل عن · بـ\% من رأس مال الشركة لامرأة واحدة أو أكثر ، وشغلت إمرأة واحدة على الأقل منصب المدير التنفيذي أو نائبه.

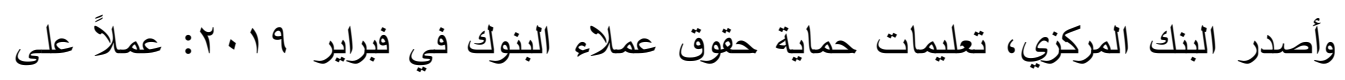
ضمان حصول العملاء على حقوقهم في كافة مراحل تعاملاتهم المصرفية، بالإضافة إلي تحسين نوعية وجودة الخدمات المالية المقدمة، كما تهدف التعليمات إلى تقديم آلية واضحة للشكاوى طرف البنوك، هرك، وتعريف العملاء بها مما يسهم في زيادة إقبالهم على التعامل مع البنوك. وأصدر البنك المركزي المصري القواعد المنظمة لتصنيف منتجات وخدمات الثمول المالي في يوليو 9 1 • r، وذلك بعد موافقة مجلس أمناء وحدة مكافحة غسيل الأموال وتمويل الإرهاب في نوفمبر

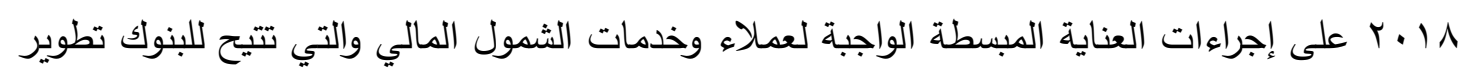
وتقديم منتجات وخدمات مصرفية منخفضة المخاطر ذات محددات معينة من خلال إجراءات مبسطة للوصول إلى الفئات المستهدفة، وذلك تنفيذاً لمبدأ المنهج القائم على المخاطر والذي تبنته مجموعة العمل المالي FATF - لاى الحديث عن الثمول المالي وكذلك وفقاً لأفضل المعايير والممارسات الدولة.

\section{مبادرة الحاضنات التكنولوحية وتطوير رواد الأعمال (إيتيدا)}

حاضنات الأعمال التكنولوجية هي إحدى برامج مركز الإبداع التكنولوجي وريادة الأعمال وتسعى إلى تحقيق مجموعة من الأهداف هي: - - تثجيع وزيادة الوعي بريادة الأعمال في قطاع الاتصالات وتكنولوجيا المعلومات. - - تأهيل المرشحين المحتملين للاحتضان. - - مشر برنامج حاضنات متكامل.

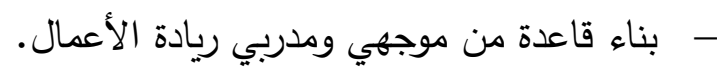
- - تطوير شبكة محلية وإقليمية ودولية من شركاء الأعمال والجهات التابعة لدعم برنامج الحاضنات. 
- ـ دعم ظهور الشركات الناشئة ذوي القدرات العالية التي يمكن أن تحقق تقدما كبيرا في التوظيف

$$
\text { والمبيعات والصادرات. }
$$

\section{رابعا : - ولتحقيق رياده الاعمال أهداف التنميه المستدامه فى مصر:-}

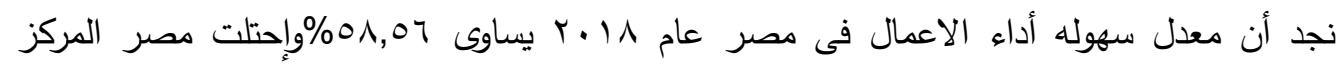
• Y ا من ضمن •9 19 دوله أما بالنسبه للدول العربيه فقد إحتلت مصر المركز الثامن بالنسبه لتصنيف تحقيق

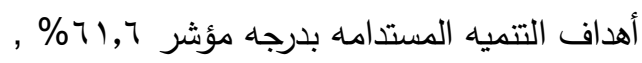

ولكى تحقق رياده الاعمال دورها فى تحقيق أهداف التتميه المستدامه لابد من توفر الشروط الاطاريه التاليه.

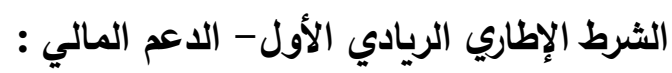

توافر الموارد المالية بأنواعها (ملكية ودين) للشركات الجديدة والنامية، بما فى ذلك الهنح والاعانات.

الثرط الإطاري الريادي الثاني- السياسات الحكومية :

مدى حيادية السياسات الحكومية، وإحتوائها على عنصرين على صعيد دعم ريادة الأعمال والتشريعات

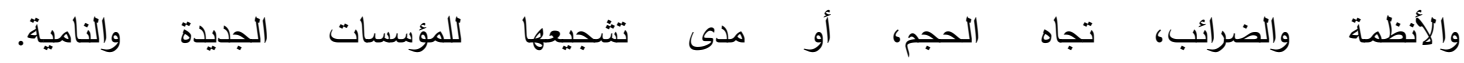
الثرط الإطاري الريادي الثالث- البرامج الحكومية الداعمة لريادة الأعمال : وجود البرامج التي تساعد الشركات الجديدة والنامية مباشرة على كافة مستويات الحكومة (الوطنية والإقليمية والبلدية،) وجودة هذه البرامج.

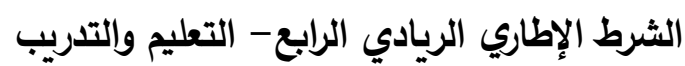

مدى دمج التدريب على إنثاء إدارة مؤسسات الأعمال الجديدة والصغيرة والنامية، في نظام التعليم والتتريب على كافة المستويات. الثرط الإطاري الريادي الخامس - نقل الأبحاث والتطوير مدى قابلية الأبحاث الوطنية والتطوير لإنتاج فرص تجارية جديدة، ومدى توفر هذه الأبحاث للمؤسسات الجديدة والصغيرة والنامية.

\section{الثرط الإطاري الريادي السادس-البنية التحتية التجارية والمهنية}

وجود خدمات تجارية ومحاسبية وخدمات في مجال حقوق الملكية إلى جانب الخدمات القانونية الأخرى، ومؤسسات تدعم أو تثجع على ظهور كيانات الأعمال الصغيرة والجديدة والنامية

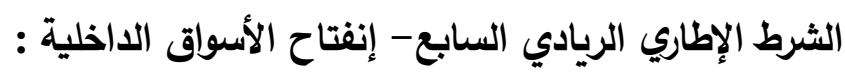
مدى خضوع الترتيبات التجارية إلى التغيير المستمر وإعادة الانتشار كلما نافست الثركات الجديدة والنامية الموردين والمقاولين والاستشاريين الحاليين، وحّلت محلهم. الثرط الإطاري الريادي الثامن - البنية التحتية المادية :

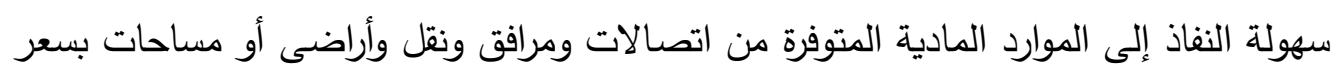
لا يتحِيز ضد المؤسسات الجديدة والصغيرة والنامية. الثرط الإطاري الريادي التاسع - المعايير الثقافية والاجتماعية: 
مدى تثجيع المعايير الاجتماعية والثقافية القائمة، أو تثبيط، الإجراءات الفردية التي قد تؤدي

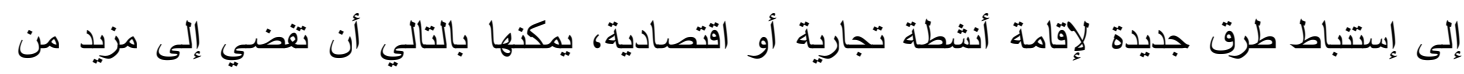

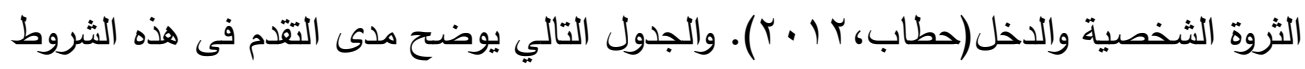
جدول(r) ملخص أداء مصر النسبى في تقييم شروط إطار ريادة الأعمال

\begin{tabular}{|c|c|c|c|c|c|c|}
\hline$r \cdot 11$ & $r .1 \mathrm{~V}$ & $r .17$ & $r .10$ & $r \cdot 1 r$ & $r \cdot 1 \cdot$ & \\
\hline$\varepsilon, r_{q}$ & $\varepsilon$ & $r, q$ & $r, 0$ & ґ,^ & $r, \wedge$ & تمويل مشاريع ريادة الأعمال \\
\hline$\varepsilon, Y \uparrow$ & $\varepsilon, Y$ & r, & r & $r, 1$ & r, $\varepsilon$ & السياسات الحكومية (الدعم والأهمية) \\
\hline$r, 0$. & r & $r, 1$ & r & - & - & السياسات الحكومية (الضرائب والبيروقراطية) \\
\hline ५, १^ & r & r & $r, 1$ & $r, Y$ & $r, r$ & البرمج الحكومية لدعم ريادة الاعمال \\
\hline 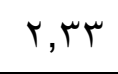 & 1,1 & $1, \mathrm{~V}$ & 1,7 & 1,7 & $r, \varepsilon$ & تعليم ريادة الاعمال فى المراحل المدرسية \\
\hline$r, V Y$ & $r, \varepsilon$ & $r, 1$ & $r, 1$ & - & - & تعليم ريادة الاعمال فى مرحلة ما بعد المدرسة \\
\hline ఛ, §५ & $r, q$ & $r, \wedge$ & $r, q$ & $r, T$ & $r, V$ & البحث والتطوير ونقل التقنية \\
\hline$\varepsilon, \varepsilon \wedge$ & $\varepsilon$ & $r, q$ & $\varepsilon, r$ & $\varepsilon, r$ & $\varepsilon, r$ & البنية التحتية التجارية والقانونية \\
\hline $0,1 \pi$ & 0,1 & 0,1 & 0,1 & 0,7 & 0,1 & ديناميكية السوق الداخلية \\
\hline$\varepsilon, \Gamma \wedge$ & $\varepsilon, 1$ & $\varepsilon$ & $r, \wedge$ & ґ,А & r, $\varepsilon$ & أعباء السوق الداخلية أو لوائح الدخول \\
\hline $7,0 Y$ & 7,1 & 7,0 & $7, r$ & $7, r$ & $7, r$ & البنية التحتية المادية \\
\hline$\{, 0\}$ & $\varepsilon$ & $\varepsilon, 1$ & $\Gamma, \Lambda$ & r, & $r, r$ & المعايير الثقافية والاجتماعية \\
\hline
\end{tabular}

ملحوظة: - الارقام فى الجدول على مقياس من 1 الى 9 وكلما ارتفع الرقم كان مؤشر جيد.حيث

$1=$

\section{من الجدول السايق نلاحظٍ}

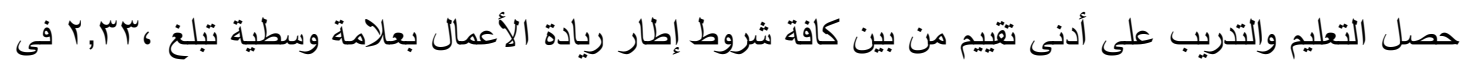

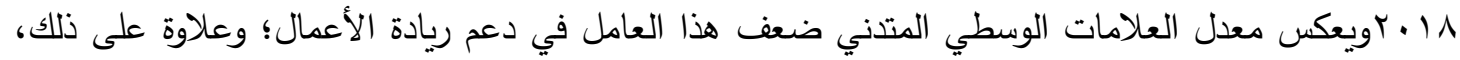

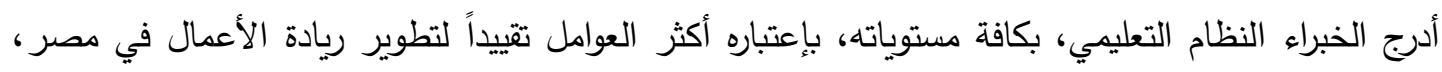

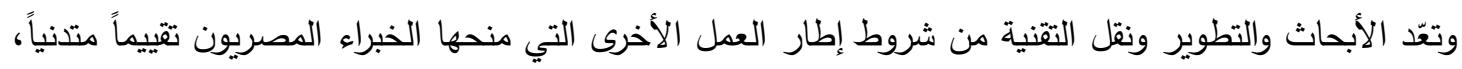

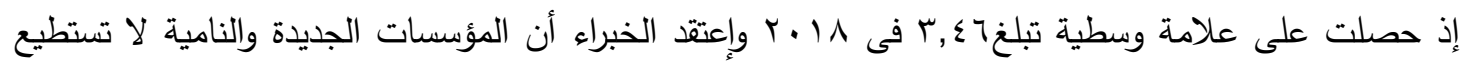

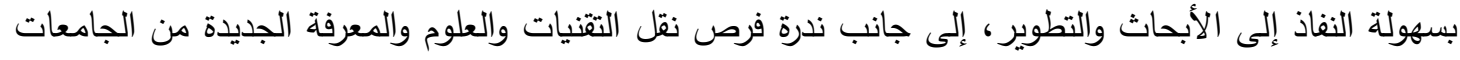

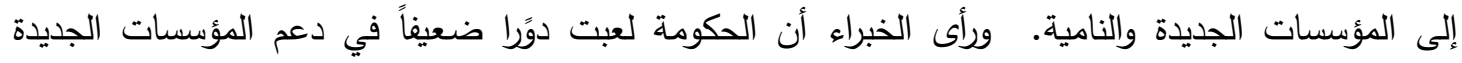

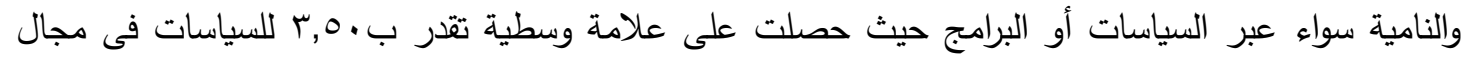

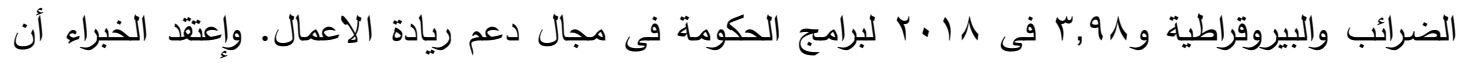


برامج الحكومة غير كافية وتفتقر إلى الفعالية، وأن السياسات غير مصممة بما يلبي الاحتياجات ويساعد رواد الأعمال المصريين على إنشاء أعمالهم وتتميتها. ثمة شرط آخر من شروط إطار عمل ريادة الأعمال إعتبره

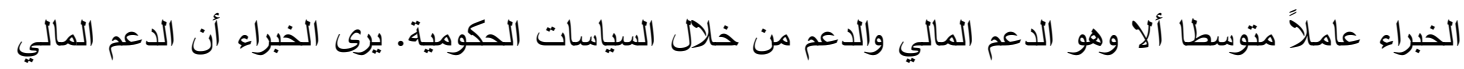

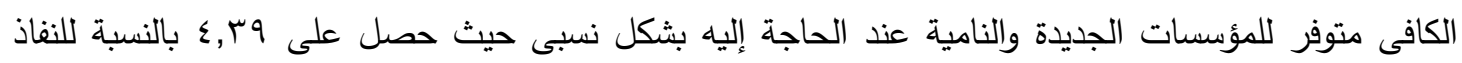

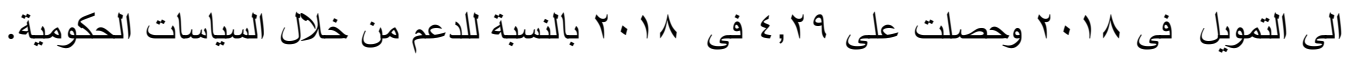

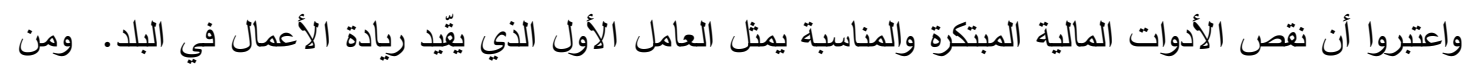

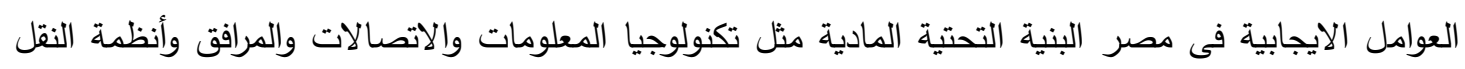

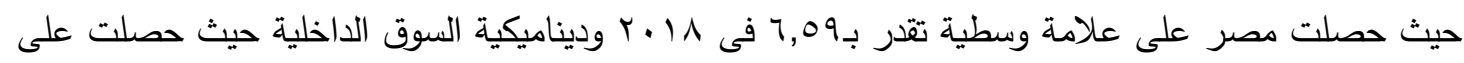

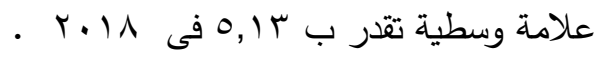
نشاط ريادة الاعمال فى مصر وأهم أسباب التوقف وأهم القطاعات التى دخلت فى ريادة الاعمال خلال

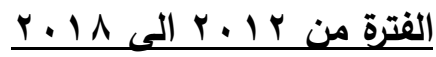

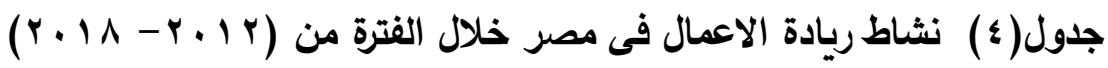

\begin{tabular}{|c|c|c|c|c|}
\hline$r \cdot 1 \wedge-r \cdot 1 V$ & $r .17$ & Y.10 & $r \cdot 1 r$ & \\
\hline$\% 7,0$ & $\% \wedge$, Ү & $\% \leq$ & $\% r, l$ & معدل ريادة الاعمال الناشئة \\
\hline$\% \vee$ & $\% ч, 7$ & $\%$ \%, & $\% \leq, 9$ & معدل ملكية الاعمال الجديدة \\
\hline 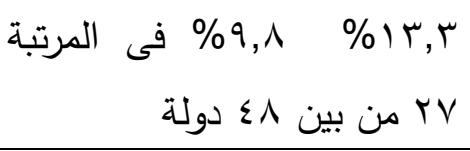 & $\%) \leq, r$ & $\% \vee, \varepsilon$ & $\% \vee, \wedge$ & معدل النشاط الريادى الاجمالى فى المراحل \\
\hline$\% \circ, V$ & $\% 7,1$ & $\% r, q$ & $\% \varepsilon, r$ & معدل ملكية الاعمال القائمة \\
\hline$\% 1 \cdot, r$ & $\% \vee, r$ & $\% \leq, \wedge$ & $\%$ \%,ч & معدل توقف الاعمال \\
\hline
\end{tabular}

-Source GEM Global Rebort 2017-2018 and GEM Egypt Reports 20122016

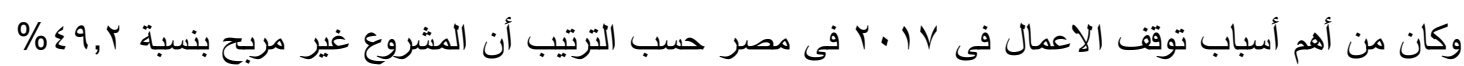

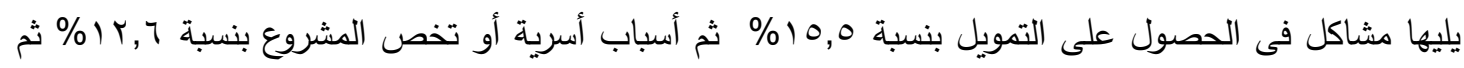

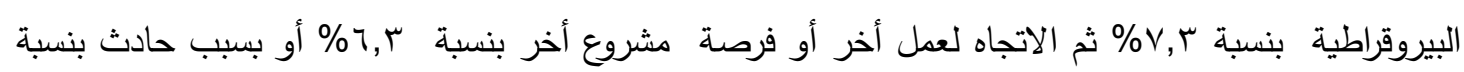

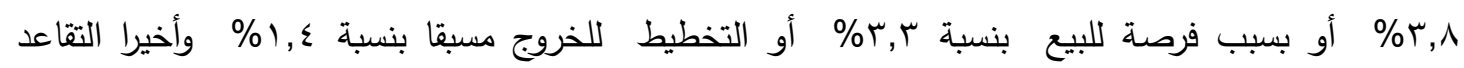

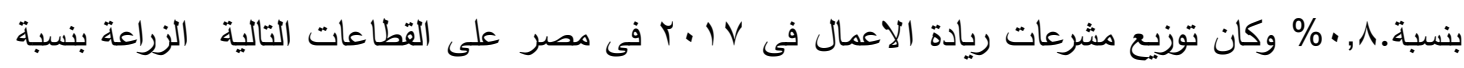

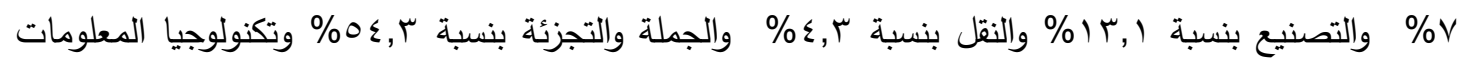
والاتصالات بنسبة ع,، •\% والتمويل بنسبة ^, ا\% و والخدمات الاحترافية بنسبة ؟, •. الخدمات الإدارية بنسبة

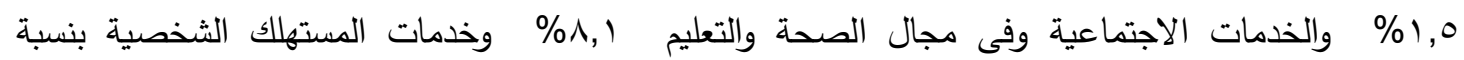
$. \% 1,9$

- خامسا: دراسة تحليليه عن أثر رياده الأعمال في تحقيق أبعاد التنمية المستدامة:- 
جدول (1) مؤشرات ريادة الاعمال والأبعاد المختلفة للتنمية المستدامة خلال الفترة من ^ .. ب الى ^1 ـ ץ فى مصر

\begin{tabular}{|r|r|r|r|r|}
\hline \multicolumn{1}{|l|}{ TEA } & HDI & GDPPC & CO2 & year \\
\hline 13.1 & 0.65 & 2497.34 & 2.49 & 2008 \\
\hline 10.05 & 0.66 & 2565.76 & 2.54 & 2009 \\
\hline 7 & 0.66 & 2644.81 & 2.44 & 2010 \\
\hline 7.4 & 0.669 & 2635.19 & 2.56 & 2011 \\
\hline 7.8 & 0.67 & 2634.85 & 2.51 & 2012 \\
\hline 7.6 & 0.68 & 2632.05 & 2.41 & 2013 \\
\hline 7.6 & 0.683 & 2648.29 & 2.23 & 2014 \\
\hline 7.4 & 0.69 & 2703.74 & 2.27 & 2015 \\
\hline 14.3 & 0.695 & 2761.38 & 2.32 & 2016 \\
\hline 13.3 & 0.696 & 2817.32 & 2.42 & 2017 \\
\hline 9.8 & 0.7 & 2907.31 & 2.52 & 2018 \\
\hline
\end{tabular}

Source: (1) World development indicators(wdi) world bank(different issuses).

(2) Global Entrepreneur Monitor(GEM)rebort(different issuses).

ملحوظة

ו CO2 emissions (metric tons per capita) :CO2 تقيس إنبعاثات ثانى أكسيد الكربون

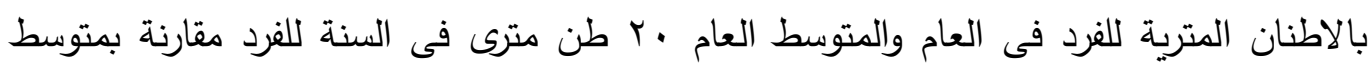
عالمى يبلغ ع أطنان كمقياس للبعد البيئى للتمية المستدامة ومدى تحقق الجودة البيئية والحد الادنى ^, ^ طن مترى فى العام.

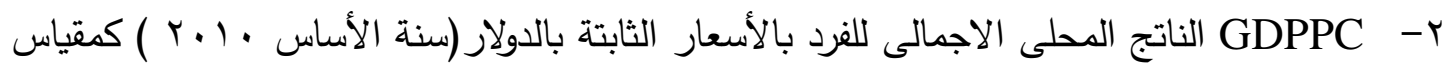
للنمو الاقتصادي الذى يمثل البعد الاقتصادي للتنمية المستدامة. r- مؤشر التتمية البشرية ويعتبر أحد المؤشرات التي (HDI ): Human development index ) تقيس البعدين الاجتماعي والاقتصادي للتنمية المستدامة حيث أنه مؤشر مركب يأخذ فى الاعتبار التعليم والدخل والعمر المتوقع ويتراوح قيمته من صفر الى الواحد الصحيح وكلما ارتفعت قيمته أرتفع مستوى التتمية الاقتصادية ع - مقياس لريادة الاعمال وهى (Total early- stage entrepreneurial Activity):TEA تمثل معدل النشاط الريادى الاجمالى وهو يقيس النسبة المئوية لعدد السكان الذين تتراوح أعمارهم

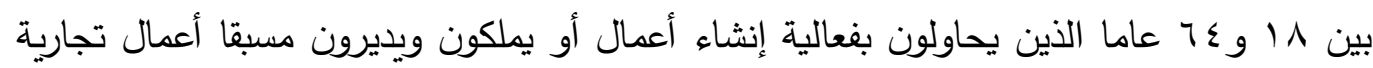
لايزيد عمرها عن ثلاثة أعوام ونصف. التعليق على الجدول السابق 
نلاحظ أن متوسط انبعاثات ثانى اكسيد الكربون للفرد فى مصر كمفياس للبعد البيئى للتمية

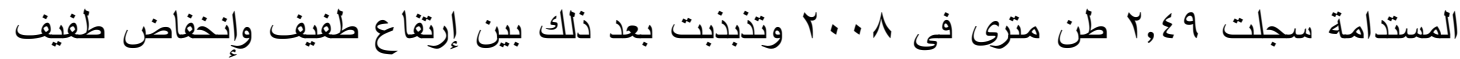

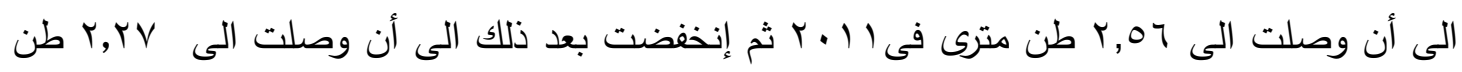

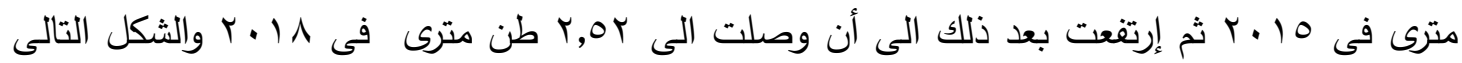

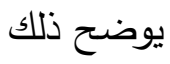

شكل (1) متوسط إنبعاثات ثانى أكسيد الكربون للفرد بالطن المترى فى مصر خلال الفترة من

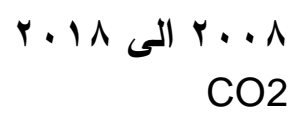

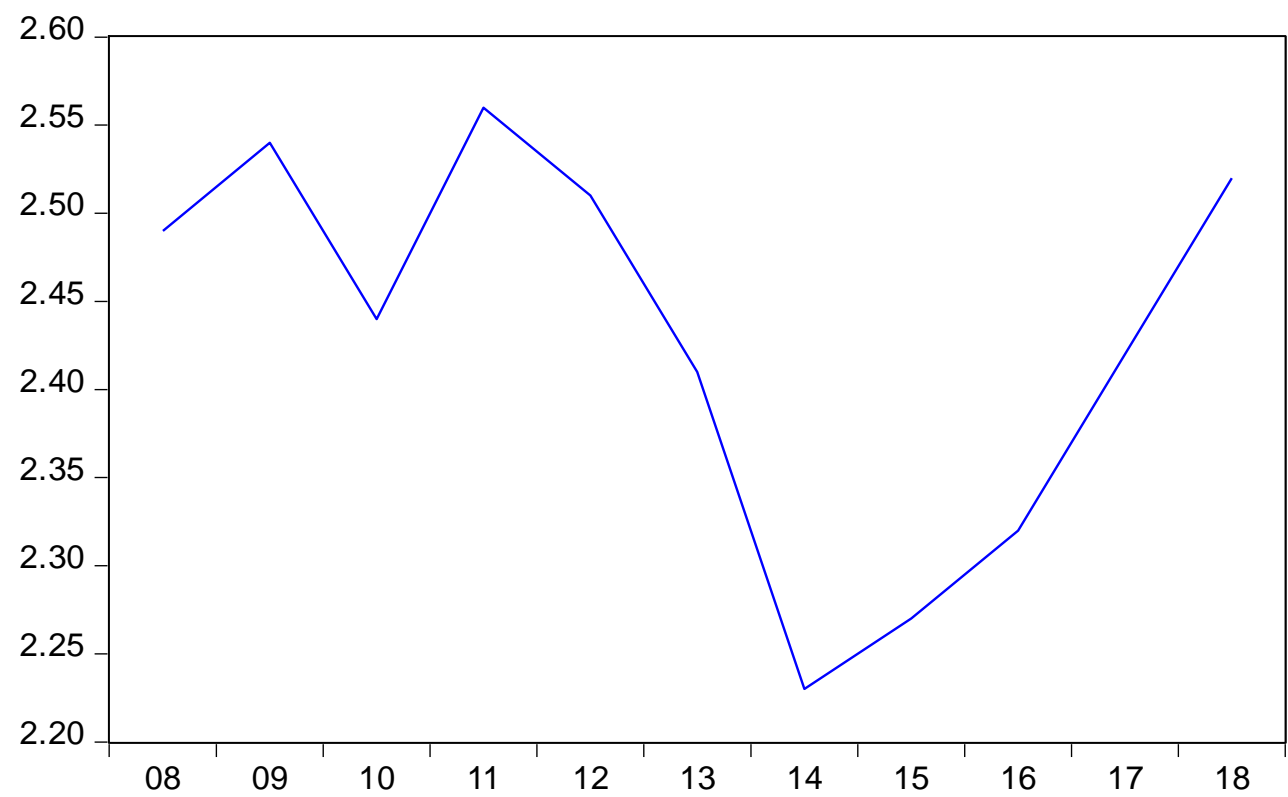

الصصدر : مرسومة بمعرفة الباحثين بإستخدام بيانات البنك الدولى بإستحدام برنامج(Eviews).

أما بالنسبة للناتج المحلى الاجمالى للفرد بالدولار فى مصر كمؤشر للنمو الاقتصادى نلاحظ إرتفاع

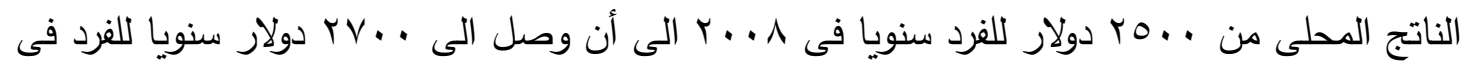

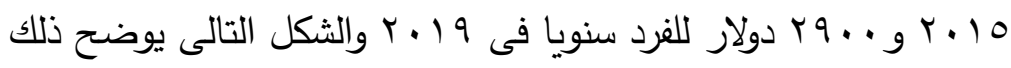

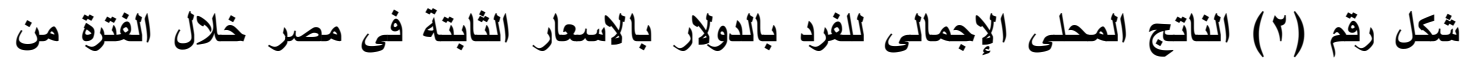

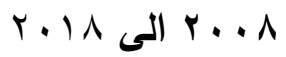


GDPPC

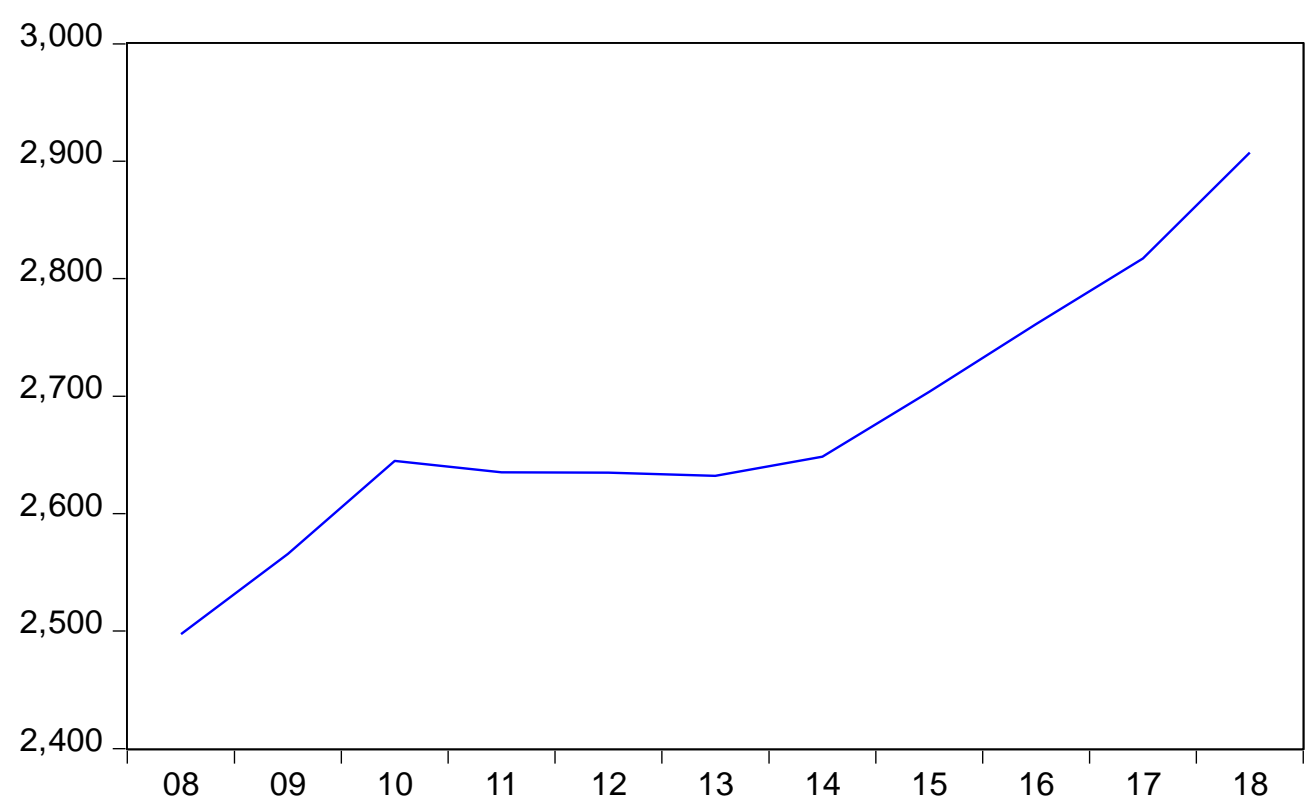

المصدر : مرسومة بمعرفة الباحثين بإستخدام بيانات البنك الدولى بإستحدام برنامج(Eviews).

وبالنسبة لمؤشر التتمية البشرية كمقياس للبعدين الاقنصادى الاجتماعى للتمية المستدامة نلاحظ

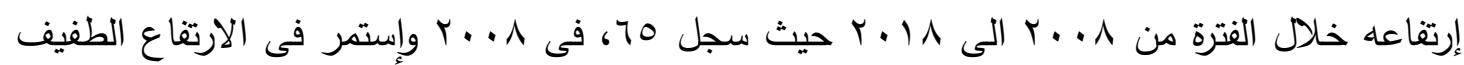

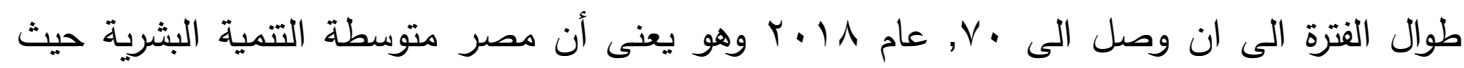

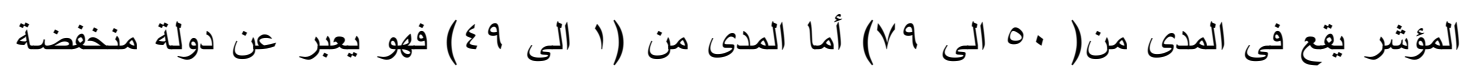
التتمية البشرية وفى المدى من (•^ الى . . (1) فهى دولة مرتفعة التنمية البشرية والثكل التالى يعبر عن ذلك

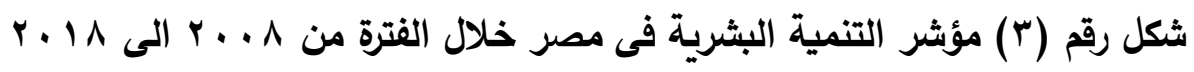


HDI

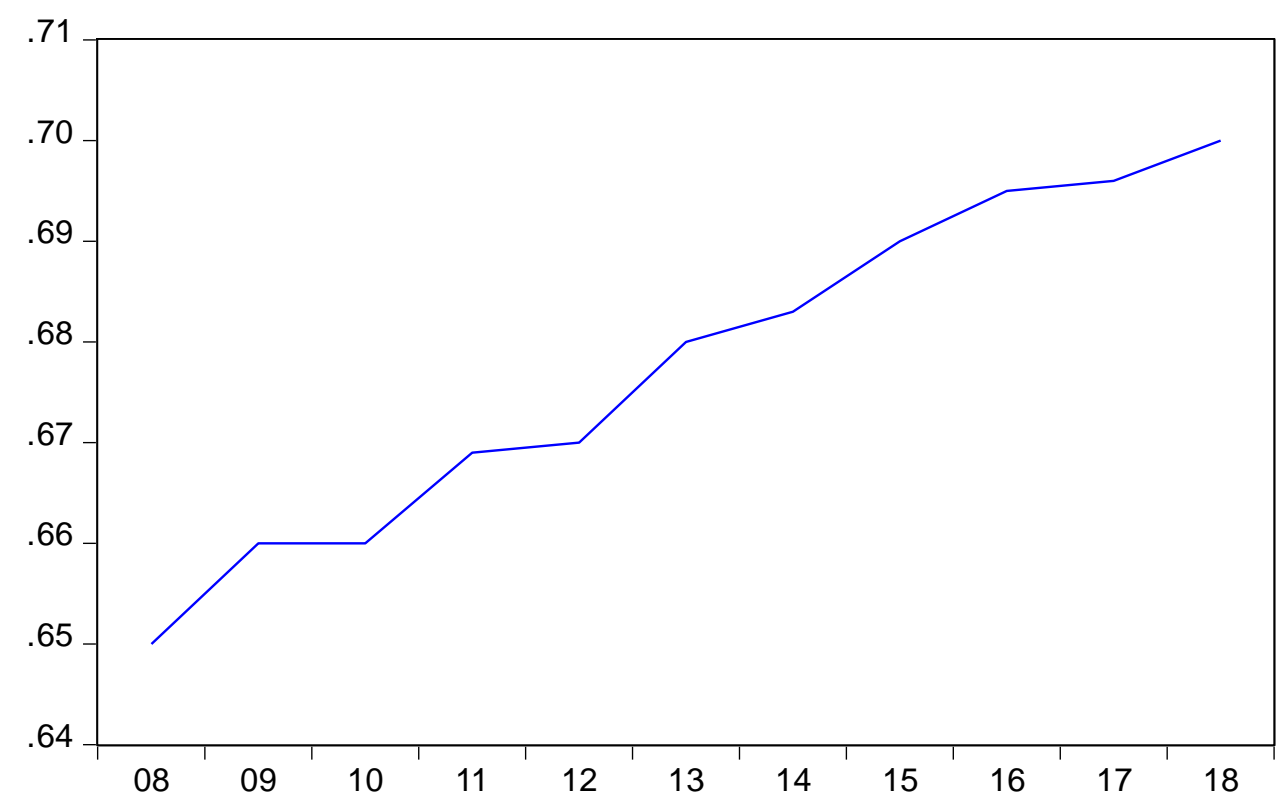

المصدر : مرسومة بمعرفة الباحثين بإستخدام بيانات البنك الدولى بإستحدام برنامج(Eviews). وبالنسبة لمعدل النشاط الريادى الاجمالى فى مصر خلال الفترة نلاحظ أنه بدء ب 13.1\% عام

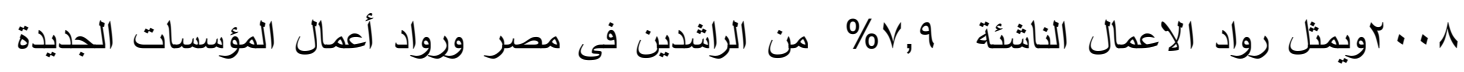

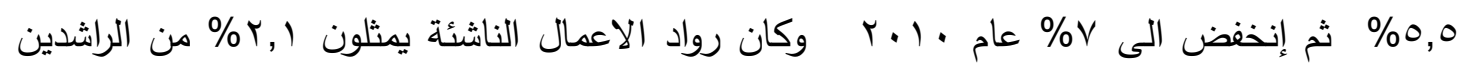

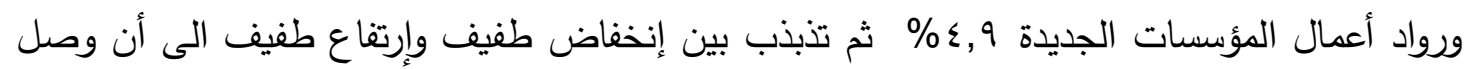

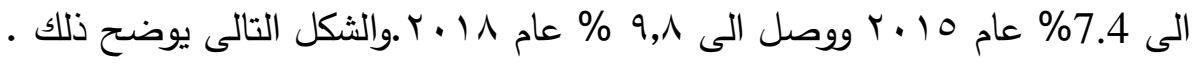

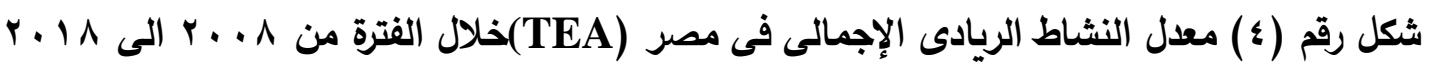


TEA

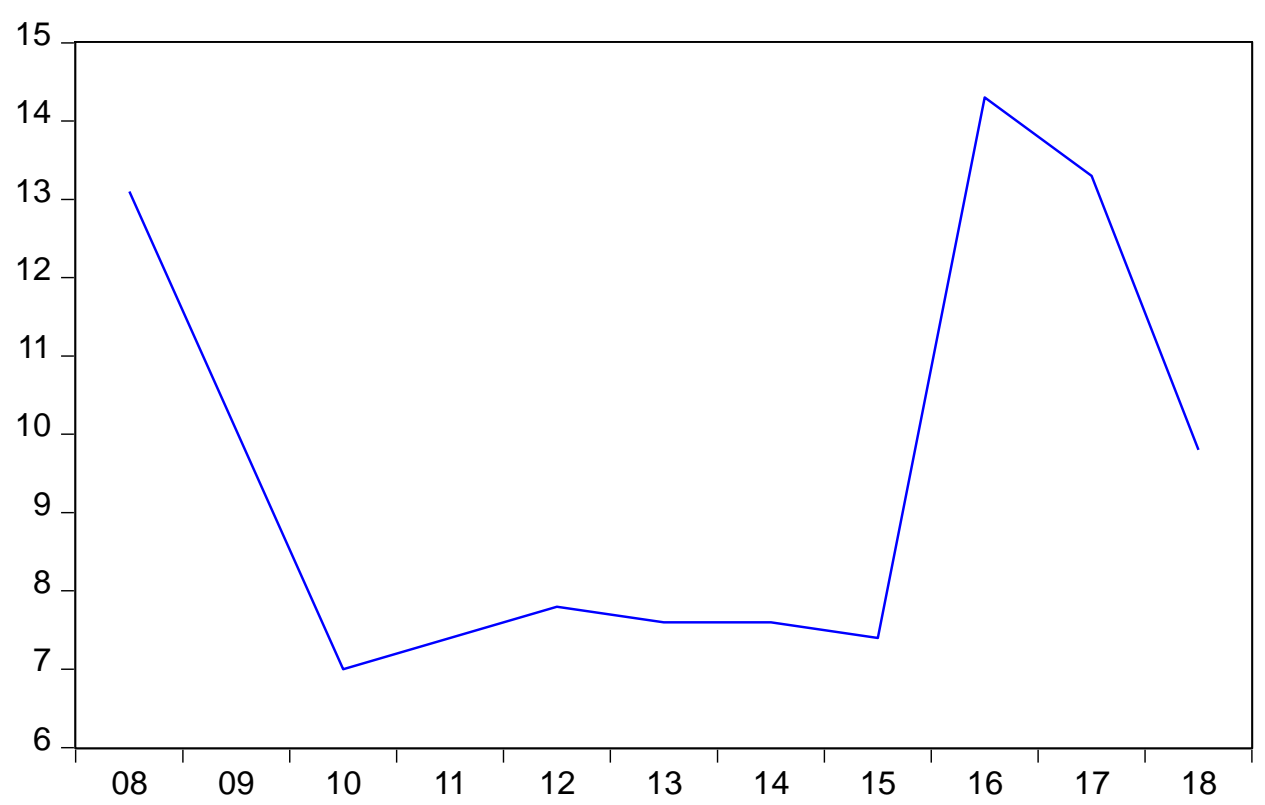

المصدر : مرسومة بمعرفة الباحثين بإستخدام بيانات البنك الدولى بإستحدام برنامج(Eviews).

وبإجراء تحليل السببية لجرانجر بين المتغيرات فى جدول البيانات السابق لتحديد إتجاه العلاقة

بين ريادة الاعمال والتتمية المستدامة فى مصر خلال الفترة المذكورة وكذلك معرفة أى المتغيرات تسبيت

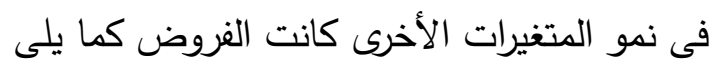
الفرض العدمى: ريادة الاعمل لا تسبب التتمية البشرية الفرض البديل: ريادة الاعمال تسبب التنمية البشرية وأيضاً الفرض العدمى: ريادة الاعمال لا تسبب النمو الاقتصادى

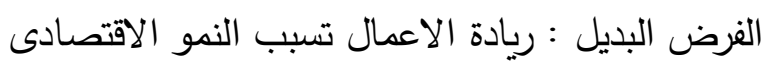
وأيضاً

الفرض العدمى : ريادة الاعمال لا تحقق الجودة البيئية الفرض البديل: ريادة الاعمال تحقق الجودة البيئية 


\begin{tabular}{cccc}
\hline \hline Prob. & F-Statistic & Obs & Null Hypothesis: \\
\hline \hline 0.0637 & 5.92340 & 9 & CO2 does not Granger Cause TEA \\
0.7778 & 0.26782 & TEA does not Granger Cause CO2 \\
\hline \hline 0.4542 & 0.96762 & 9 & HDI does not Granger Cause TEA \\
0.0432 & 7.62711 & TEA does not Granger Cause HDI \\
\hline \hline
\end{tabular}

\section{Pairwise Granger Causality Tests}

Lags: 1

\begin{tabular}{rrrr}
\hline \hline Prob. & F-Statistic & Obs & Null Hypothesis: \\
\hline \hline 0.2888 & 1.31726 & 10 & GDPPC does not Granger Cause TEA \\
0.0506 & 5.55256 & TEA does not Granger Cause GDPPC \\
\hline \hline
\end{tabular}

ومن الجدول السابق نلاحظ ما يلى

1- إن ريادة الاعمال تسبب التنمية البشرية وبالتالى تؤثر فى البعدين الاقتصادى والاجتماعى من أبعاد التتمية المستدامة وبالتالى تؤثر فى التتمية المستدامة.

ץ- أن ريادة الاعمل مسبب من مسببات النمو الاقتصادى وهو ما يتقق مع النظرية الاقتصادية والدراسات السابقة وبالتالى تئثر فى تحقيق التتمية المستدامة.

ب- أن العلاقة بين ريادة الاعمال ومدى تحقق الجودة البيئية وهى تمثل البعد البيئى للتمية المستدامة نلاحظ أن التاثير يتجه من البعد البيئى الى ريادة الاعمال أى أن مدى توافر بيئة جيدة يدعم ريادة الاعمال فى مصر وعموما العلاقة أحادية الاتجاه فى كل العلاقات السابقة. كيفية إستخدام ريادة الأعمال كسياسة هامة لتحقيق أهداف التنمية المستدامة السبعة عشر : 1- زيادة الوعى بأهمية المشاريع الصغيرة والمتوسطة وزيادة إهتمام البنوك التجارية بالمتطلبات التمويلية للمشاريع الصغيرة المتوسطة ووضع الخطط التمويله لها وبذلك تستطيع المشاريع الصغيرة والمتوسطة تحقيق الهدف الأول ، حيث توفر هذه المشاريع فرص عمل فتضمن الحصول على دخل للأفراد ، والهدف الثانى ، حيث ضمان الحصول على دخل يؤدى الى القضاء على الجوع • والهدف الثالث ، وهو الرعاية الصحية والهدف الخامس ، حيث أن المشاريع الصغيرة والمتوسطة باتت تمكن المرأة من إقامة هذه المشاريع مما يحقق المساواة بين الجنسين. r- تطوير تفكير الثباب من التركيز على إستغلال الفرص الى التفكير لخلق الفرص وحث الثباب على الابتكار • ووضع الخطط لإستغلال قدرات الثباب منذ الصغر أملا فى زيادة رواد العمال وزيادة الدعم للمبدعين مما يساعد على الابتكار ـ مما يحقق الهدف السابع وذلك بإختراع مصادر

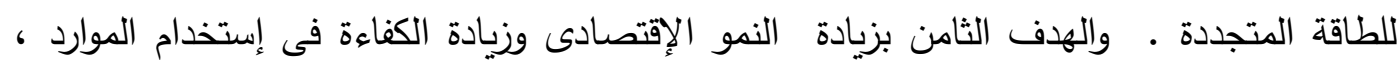
والهدف التاسع و الهدف الثانى عشر • 
ץ- تفعيل حاضنات الثباب بجانب حاضنات الأعمال بمثابة مختبرات لبناء شخصية العناصر الريادية وتطوير آليات التطوير لاى مؤسسات التعليم وبذلك يحقق الهدف الرابع • ع - يجب على الحكومة المصرية تطوير منظومة التخطيط الكلى حتى يكون هناك تنسيق بين كافة

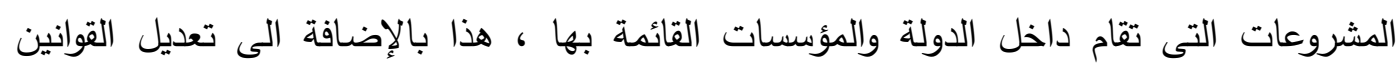

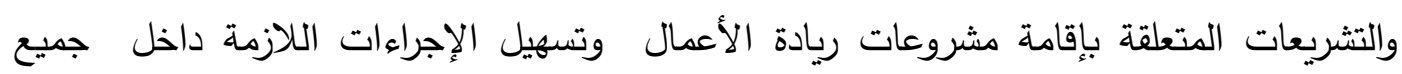
المحافظات مما يعمل على تحقيق الهدف العاشر والهدف الحادى عشر . 0- التركيز على التعليم الفنى وإدراج رياده الاعمال فى المناهج مما يخلق جيل قادر على الابتكار ويفى بمتطلبات سوق العمل والاهتمام بالمناهج التى تهتم بالبيئه مما يساعد فى تحقيق الأهداف الثالث عشر و الرابع عشر والخامس عشر. צ- الحد من الروتين الادارى فى إنجاز المعاملات ,حيث ينبغى على الحكومات أن تقدم أنواعا كثيره من الدعم لجميع أنواع منظمى المشاريع , مع التركيز على الخطوات الاداريه اللازمه لإقامه الإداه

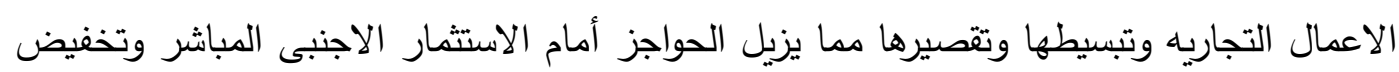
الحد الادنى من متطلبات رأس المال لبدء النشاط التجارى مما يحقق الهدف الثامن والهدف السابع عشر V- توسيع نطاق الدعم الموجه لريادة الأعمال بحيث يصل إلى المناطق النائية والحدودية فكلما إتسع نطاق رواد الأعمال داخل الدولة الواحدة كلما تم القضاء على التمييز داخل الدولة.

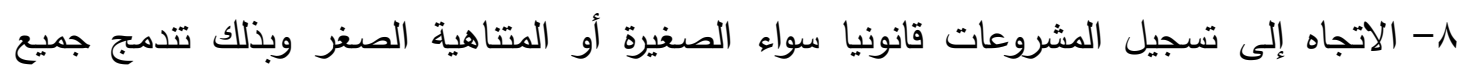
المشروعات تحت نطاق الاقتصاد الرسمي مما يرفع معدل النمو الاقتصادي.

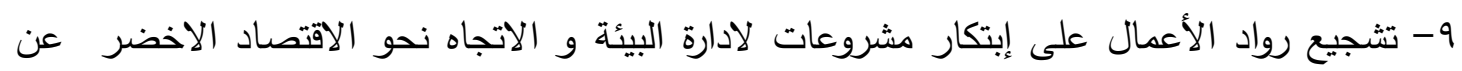
طريق إتجاه رواد الاعمال الى إعتماد النظم البيئيه وإستثمارات بيئيه جديده والاهتمام بالمياه النظيفه الإدهاه وخدمات الصرف الصحى وهى ما يحقق الهدف السادس والسابع. 


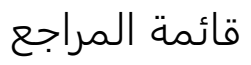

قائمة المراجع العربية

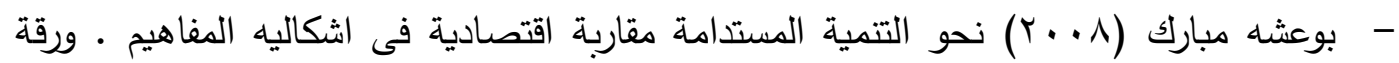
عمل مقدمة إلى المؤتمر العلمى الدولى التتمية المستدامة والكفاءة الاستخدامية للموارد المتاحة 11-V ,

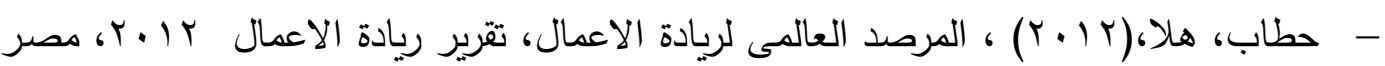

- - سهام حرفوش وأخرون ,الاطار النظرى للتميه المستدامه ومؤشرات قياسها ,المؤتمر العلمى

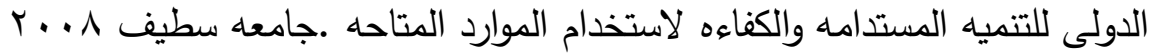
- طارق المصرى ، واقع حاضنات الأعمال التكنولوجية فى تعزيز الريادة وتحقيق التنمية المستدامة فى مؤسسات التعليم ( العالى ) مؤته للبحوث والدراسات - سلسلة العلوم الإنسانية

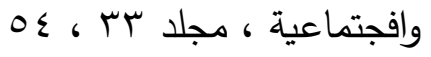

- عبدربه ، وجدى محمدى ، الإعداد الجيد للمنظم كوسيلة للقضاء على البطالة وتحقيق النمو

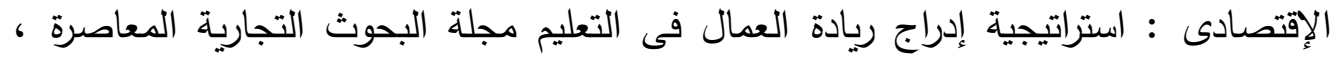

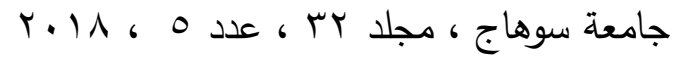
- - محمد محمود يوسف,قياس تأثير المؤسسات على العلاقه بين رياده الاعمال والنمو الاقتصادى

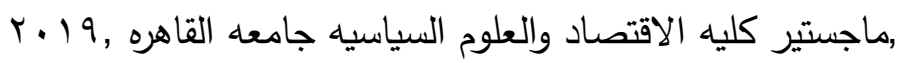

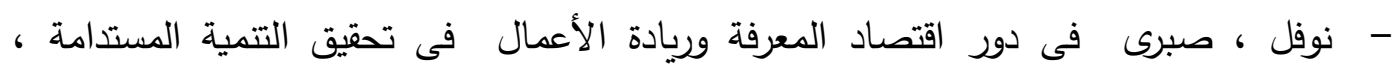

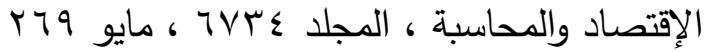
- - هانى مصطفى الثامى,نظريه الاساس الثلاثى وأمكانيه تطبيقها فى التتميه الاقتصاديه , مجله التجاره والتمويل ,كليه التجاره جامعه طنطا, العدد الثانى 9 1. بـ. - يمن الحماقى , رياده الاعمال والتمكين الاقتصادى للمرأه, أعمال ملتقيات المرأه العربيه فى جى

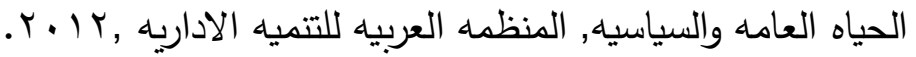
-

- Adel Ben Youssef, Sabri Boubaker, Anis Omri, "Entrepreneurship and sustainability: The need for innovative and institutional solutions", Technological Forecasting and Social Change, Volume 129, April 2018, Pages 232-241

- c.makropoulos , e.rozos , i.tsoukalas , 1. karajiannidis , e.makri , c.lioumis , c.noutsopoulos, d.mamais, c.rippic, e.lytras : a water research option supporting circular economy, public serves provision and entrepreneurship , journal of environmental management , 2018 
- Christopher Brown and Mark Thornton . How Entrepremeurship theory created economics the quaktelly journal Austrian economic vol16 n41 2013

- Claudia s.l.dias, Ricardagouvela , joaoj what's new in the research on egricultural entrepreneurship jornal of rurlrural studies , 2019

- Daniela Stefanescu, Angela On "Sustainable development and entrepreneurship: Past contributions and future directions", Procedia Social and Behavioral Sciences, Volume 58, 12 October 2012, Pages 889-898

- David L. Poole, "Entrepreneurs, entrepreneurship and SMEs in developing economies: How subverting terminology sustains flawed policy", World Development Perspectives, Volume 9, March 2018, Pages 35-42

- Desirée F. Pacheco, Thomas J. Dean, David S. Payne, "Escaping the green prison: Entrepreneurship and the creation of opportunities for sustainable development", Journal of Business Venturing, Volume 25, Issue 5, September 2010, Pages 464-480

- Egypt voluntary national review 2018

- Future research, technalagical for casting, social change 149.2019

- Gheorghe Zaman, Valentina Vasile, Anca Cristea, "Oustanding Aspects of Sustainable Development and Competitiveness Challenges for Entrepreneurship in Romania", Procedia Economics and Finance, Volume 3, 2012, Pages 12-17

- Global Entrepreneurship Monitor(GEM)Global Report(different issues).

- Global Entrepreneurship Monitor (GEM) Egypt national report 20152016

- Global Entrepreneurship Monitor (GEM) Egypt national report 20162017

- Global Entrepreneurship Monitor (GEM) Egypt national report 20172018

- Global Entrepreneurship Monitor 2018- 2019 Global Report

- http://www.cabinet.gov.eg/Arabic/GovernmentStrategy/Pages/TheStrategy-of-Dr.Mostafa-Madbouly's-government.aspx

- Jack Mason, "Entrepreneurship in knowledge-based services: Opportunity and challenges for new venture, economic, and workforce development", Journal of Business Venturing Insights, Volume 10, November 2018, Article e00092

- Jannic Horne, Malte Recker, Ingo Michel felder, Jason Jay, Jan Kratzer, "Exploring entrepreneurship related to the sustainable development goals - mapping new venture activities with semi-automated content analysis", Journal of Cleaner Production, Volume 242, 1 January 2020, Article 118052 
- lenox.m.J,york.1.g, Environmental enzeleysenutship ,theefordfond book of business and thee natural enviromentatl , exford university,2011

- Maia Lordkipanidze, Han Brezet, Mikael Backman, "The entrepreneurship factor in sustainable tourism development", Journal of Cleaner Production, Volume 13, Issue 8, June 2005, Pages 787-798

- MihaelaKardos, "The Relationship between Entrepreneurship, Innovation and Sustainable Development, Research on European Union Countries", Procedia Economics and Finance, Volume 3, 2012, Pages 1030-1035

- N. Öyküİyigün, "What could Entrepreneurship do for Sustainable Development? A Corporate Social Responsibility-Based Approach", Procedia - Social and Behavioral Sciences, Volume 195, 3 July 2015, Pages 1226-1231

- Nortroig -tierno, joaquinalacazor, use of in frost cltures to support innovative entrepreneurship and business growh, journel of business ,68, 2015

- R. Cervelló-Royo, I. Moya-Clemente, M. R. Perelló-Marín, G. RibesGiner "Sustainable development, economic and financial factors, that influence the opportunity-driven entrepreneurship. An fsQCA approach", Journal of Business Research, In press, corrected proof, Available online 8 November 2019

- Rama krishnareddykammitha : Smart cities and entrepreneurship : an a genda for

- Richard S. Aquino, Michael Lück, Heike A. Schänzel, “A conceptual framework of tourism social entrepreneurship for sustainable community development", Journal of Hospitality and Tourism Management, Volume 37, December 2018, Pages 23-32

- Rosalinde Klein Woolthuis, Fransje Hooimeijer, Bart Bossink, Guus Mulder, Jeroen Brouwer, "Institutional entrepreneurship in sustainable urban development: Dutch successes as inspiration for transformation", Journal of Cleaner Production, Volume 50, 1 July 2013, Pages 91-100

- Sabrine Dhahri, Anis Omri, "Entrepreneurship contribution to the three pillars of sustainable development: What does the evidence really say?", World Development, Volume 106, June 2018, Pages 64-77

- SDG accelerator and bottleneck assessment, United Nations Development programme

- Siqing Shan, YingweiJia, Xianrong Zheng, XiaoboXu, "Assessing relationship and contribution of China's technological entrepreneurship to socio-economic development", Technological Forecasting and Social Change, Volume 135, October 2018, Pages 83-90 
- Suyash jolly, Petrsbodniak, r.p.j.m raven institutional entrepreneurship in transforming energy systems tawards sustainability, energy research \&social science 2016.17

- Vanessa rattem, peturususamani, - entrepreneurship education : time for a change in research direction, the international journal of management education 2020

- World Development Indicators(wdi) world bank(different issues).3-

- Xueqin Wang, Kum Fai Yuen, YiikDiew Wong, Kevin X. Li "How can the maritime industry meet Sustainable Development Goals? An analysis of sustainability reports from the social entrepreneurship perspective", Transportation Research Part D: Transport and Environment, Volume 78, January 2020, Article 102173

- Zacharoula And reopoulou, Georgios Tsekouropoulos, Alexandros The odoridis, Vagis Samathrakis, Christos Batzios, "Consulting for Sustainable Development, Information Technologies Adoption, Marketing and Entrepreneurship Issues in Livestock Farms", Procedia Economics and Finance, Volume 9, 2014, Pages 302-309 